\title{
Prefrontal spatial working memory network predicts animal's decision making in a free choice saccade task.
}

\author{
AUTHOR(S):
}

Mochizuki, Kei; Funahashi, Shintaro

\section{CITATION:}

Mochizuki, Kei ... [et al]. Prefrontal spatial working memory network predicts animal's decision making in a free choice saccade task.. American Physiological Society 2016, 115(1): 127-142

ISSUE DATE:

2016-01-01

URL:

http://hdl.handle.net/2433/208399

\section{RIGHT:}

(c) 2016 the American Physiological Society; This is the accepted manuscrip of the article is available at http://dx.doi.org/10.1152/jn.00255.2015; ; The full-text file will be made open to the public on $1 \mathrm{January} 2017$ in accordance with publisher's 'Terms and Conditions for Self-Archiving'; この論文は出版社版でありません。引用の際に は出版社版をご確認じ利用ください。; This is not the published version. Please cite only the published version. 


\section{Prefrontal spatial working memory network predicts}

2 animal's decision-making in a free choice saccade task.

3 Kei Mochizuki $^{1}$ and Shintaro Funahashi ${ }^{1,2}$

4 1. Kokoro Research Center,

5 Kyoto University, Kyoto, Japan.

6 2. Laboratory of Cognitive Brain Science,

7 Department of Cognitive and Behavioral Sciences,

8 Graduate School of Human and Environmental Studies,

9 Kyoto University, Kyoto, Japan.

10 Running Head: Decision-making in a free choice saccade task

11 Address for Correspondence:

12 Shintaro Funahashi

13 Kokoro Research Center, Kyoto University

1446 Yoshida-Shimoadachi-cho, Sakyo-ku, Kyoto 606-8501, Japan

15 funahashi.shintaro.2z@kyoto-u.ac.jp 


\section{Abstract}

17 While neurons in the lateral prefrontal cortex (PFC) encode spatial information during

18 the performance of working memory tasks, they are also known to participate in

19 subjective behavior such as spatial attention and action selection. In the present study,

20 we analyzed the activity of primate PFC neurons during the performance of a free

21 choice memory-guided saccade task in which the monkeys needed to choose a saccade

22 direction by themselves. In trials when the receptive field location was subsequently

23 chosen by the animal, PFC neurons with spatially selective visual response started to

24 show greater activation before cue onset. This result suggests that the fluctuation of

25 firing before cue presentation prematurely biased the representation of a certain spatial

26 location, and eventually encouraged the subsequent choice of that location. In addition,

27 modulation of the activity by the animal's choice was observed only in neurons with

28 high sustainability of activation, and was also dependent on the spatial configuration

29 of the visual cues. These findings were consistent with known characteristics of PFC

30 neurons in information maintenance in spatial working memory function. These results

31 suggest that pre-cue fluctuation of spatial representation was shared and enhanced

32 through the working memory network in the PFC, and could finally influence the

33 animal's free choice of saccade direction. The present study revealed that the PFC

34 plays an important role in decision-making in a free choice condition, and that the

35 dynamics of decision-making is constrained by the network architecture embedded in

36 this cortical area. 
37 Keywords:

38 Prefrontal cortex, Spatial representation, Decision-making, Memory-guided

39 saccade

40 


\section{Introduction}

42 Neurophysiological investigations of the prefrontal cortex (PFC) have shown that

43 neurons in the lateral PFC exhibit a persistent activation during the delay period

44 (delay-period activity) when the monkey is remembering a particular spatial location

45 in memory-guided saccade tasks (Funahashi et al. 1989, 1990, 1991, 1993b;

46 Goldman-Rakic et al. 1990; Constantinidis et al. 2001a, 2001b). This delay-period

47 activity has been proposed to be a neuronal correlate of active maintenance of

48 visuospatial information. The role of the PFC in information maintenance has been

49 further supported by lesion studies in monkeys (Funahashi et al. 1993a; Sawaguchi

50 and Iba 2001) and humans (D'Esposito and Postle 1999; Mottaghy et al. 2002; Müller

51 et al. 2002), and by functional brain imaging studies (Courtney et al. 1998; Zarahn

52 et al. 1999, 2000; Sakai et al. 2002). Thus, the maintenance of task-relevant spatial

53 information could be one of the key features that could help us to understand the

54 function of the PFC (Fuster 2008).

55 Spatially selective activity of PFC neurons has also been proposed to be related to

56 decision-making process such as response selection (Rowe et al. 2000) and spatial

57 attention (Lebedev et al. 2004; Messinger et al. 2009). Especially, in human

58 neuroimaging studies, the PFC has been reported to play a role in self-initiated

59 behavior and internally-driven decision-making (Frith et al. 1991; Hyder et al. 1997;

60 Lau et al. 2004a, 2004b; Haynes et al. 2007; Soon et al. 2008). Therefore, the known 
61 characteristic activation of spatially selective PFC neurons could also be related to 62 decision-making under these situations. Previous studies have investigated the 63 neuronal underpinning of decision-making under these situations in the PFC 64 (Watanabe et al. 2006; Watanabe and Funahashi 2007) and other related areas such as 65 frontal eye field, supplemental eye field and lateral intraparietal cortex (Coe et al. 66 2002). These studies reported that the activity of spatially selective neurons is related to the animal's own decision about saccade direction. However, in these studies, a

68 fixed set of spatial locations were repeatedly presented as options for a saccade in a 69 block of trials. Under this setup, presentation of the spatial cues was less informative 70 since the available saccade directions were obvious without seeing the actual cue 71 presentation. The monkey could indeed decide the saccade direction before the 72 presentation of the visual cues. In addition, due to the predetermined and less various 73 configuration of the cues, precise analysis about the relationship between neuron's 74 receptive field and chosen location was limited. Therefore, further experiment which 75 enables a close examination of how prefrontal working memory network represents 76 multiple spatial information and how the activity of PFC neurons is related to the 77 animal's own decision about saccade direction is needed.

78 In the present study, we established a free choice memory-guided saccade task in 79 which the monkeys by themselves chose the direction of the saccade among multiple 80 locations changing trial to trial. By varying the options for a choice in each trial, we 81 could examine the precise time course of decision-making process taken in the 
82 network of spatially selective PFC neurons. We found that the activity of lateral PFC

83 neurons could predict the animal's decision about subsequent eye movement direction

84 even before cue presentation. This suggests that pre-existing activation state of PFC

85 neurons immediately before cue presentation influenced the construction of spatial

86 representation, and eventually biased the animal's subsequent choice of the saccade

87 direction. Furthermore, we found that the impact of neuron's activity on the animal's

88 choice was stronger in neurons that showed greater persistent activity in a control

89 spatial working memory task. In addition, while PFC neurons tended to represent

90 unchosen spatial location more weakly from the beginning of the trial, this suppression

91 of unchosen location was modest when chosen and unchosen locations were placed in

92 the same side of the visual field. This finding was in accord with the known

93 contralateral organization of spatial working memory network in the PFC. These

94 results indicate that the role of PFC neurons in a free choice of saccade direction is

95 linked to their firing property and network background as a neuronal underpinning of

96 spatial working memory function. Our present study showed a possible overlap of

97 cellular mechanisms for maintenance and decision-making of spatial information, and

98 offers a clue to a further investigation on the nature of the spatial information

99 processing taken place in the PFC. 


\section{$100 \quad$ Materials and Methods}

\section{$101 \quad$ Animals}

102 We used two female Japanese monkeys (Macaca fuscata; monkeys $\mathrm{O}$ and $\mathrm{E}$ ). The

103 monkeys were housed in individual stainless steel home cages. Water intake was 104 restricted in the home cage and provided as a reward in the laboratory. Additional 105 vegetables and fruits were provided to fulfill the daily requirement of water intake if 106 necessary. All experimental procedures were conducted in accordance with the 107 guidelines provided by the Primate Research Institute of Kyoto University and were 108 approved by the Animal Research Committee at the Graduate School of Human and 109 Environmental Studies, Kyoto University.

\section{Apparatus}

111 During experimental sessions, the monkey sat in a primate chair in a dark

112 sound-attenuated room with its head movements restricted by a head-holding 113 apparatus. We used TEMPO software (Reflective Computing, Olympia, WA, USA)

114 for task control and data acquisition. Visual stimuli were presented on a 20-inch CRT 115 monitor (Dell UltraScan D2026T-HS, Dell, Round Rock, TX, USA) that was placed

$11640 \mathrm{~cm}$ from the subject's face. A scleral search coil system (Enzanshi Kogyo, Tokyo, 117 Japan) was used to monitor the monkeys' eye movements (Robinson 1963; Judge et al. 118 1980). 


\section{Tasks}

120 We used two types of memory-guided saccade tasks (Fig. 1a): an Instructed Choice

121 Task (ICT) and a Free Choice Task (FCT). The tasks were similar to those used in

122 previous studies (Watanabe et al. 2006; Watanabe and Funahashi 2007; Mochizuki and

123 Funahashi 2014). In both tasks, a trial started with the presentation of a fixation point

124 (white cross, $0.5^{\circ}$ in visual angle) at the center of the monitor. After the monkey

125 maintained fixation on the fixation point for $1.0 \mathrm{~s}$ (fixation period), eight peripheral

126 targets (white cross, $\left.0.75^{\circ}\right)$ were presented at an eccentricity of $13^{\circ}\left(0^{\circ}-315^{\circ}\right.$,

127 separated by $45^{\circ}$ ). The monkey had to neglect these targets and keep watching the

128 fixation point for another $1.0 \mathrm{~s}$ (pre-cue period). Next, one or two visual cues (filled

129 white circle, $2.5^{\circ}$ ) were briefly blinked over the peripheral targets for $0.5 \mathrm{~s}$ (cue

130 period). In the ICT, one cue was presented at one of the eight target locations. In the

131 FCT, two identical cues were simultaneously presented at two peripheral locations.

132 After the cues disappeared, the monkey had to maintain fixation for 1.5-3.0 s random

133 length of delay (delay period). At the end of the delay period, the fixation point was

134 turned off, and the monkey was required to make a memory-guided saccade toward the

135 cued location within $0.5 \mathrm{~s}$. The reward was delivered after the monkey maintained

136 fixation on the correct target location for $0.3 \mathrm{~s}$. In FCT trials, a saccade to either of the

137 two locations was regarded as correct. Every correct response was rewarded by a drop

138 of juice, and there was no difference in the amount of reward regardless of the

139 monkey's choice in the FCT or the type of the task. 
140 The location of the cue in ICT trials was randomly determined as one of the eight

141 peripheral target locations. Possible cue locations in FCT trials were limited to four 142 locations $\left(0^{\circ}, 90^{\circ}, 180^{\circ}\right.$ and $\left.270^{\circ}\right)$ to reduce the number of combinations of cue 143 locations. In an FCT trial, cues were presented at two of these four possible locations. 144 Accordingly, trials consisted of eight cue conditions in the ICT and six pair conditions 145 in the FCT. ICT and FCT trials were intermingled in random order.

146 During a recording session, we first presented only ICT trials using the eight 147 possible cue locations as explained above. After we isolated the activity of a single 148 neuron, we examined whether it had a directionally selective task-related activity 149 during performance of the ICT. We collected on average 8.3 trials for each of the eight 150 direction conditions for this screening. We then quantitatively analyzed the activity of 151 the neuron during several task epochs: cue (0-500 ms after the onset of the cue), early 152 delay (0-1000 ms after the start of the delay), late delay (1000-500 ms before the end 153 of the saccade), early response (300-0 ms before the end of the saccade) and late 154 response (0-300 $\mathrm{ms}$ after the end of the saccade). If the neuron exhibited a 155 significantly different firing rate during any of these epochs compared to the baseline 156 period (0-1000 ms before the onset of the cue, Dunnett's test for multiple comparisons, $157 p<.05)$, we categorized it as a task-related neuron. The neuron was then further tested 158 for directional selectivity. We used a modified circular normal distribution (von Mises 159 distribution) as a tuning curve to evaluate the modulation of the neuron's firing rate 160 across the eight cue conditions: 


$$
\mathrm{f}(d \mid \mu, \beta, B, R)=B+R \cdot \frac{\exp (\beta \cdot \cos (d-\mu))}{\exp (\beta)}
$$

162 where the firing rate of a neuron (f) was determined as a function of the direction of 163 the cue $(d)$, based on the baseline $(0 \leq B)$ and magnification $(R)$ factors for the firing 164 rate, and the location $(\mu)$ and concentration $(0 \leq \beta)$ factors for the von Mises distribution. 165 The peak direction estimated as the $\mu$ parameter by fitting of the tuning curve during 166 the epoch in which the firing rate was highest was regarded as the neuron's preferred 167 direction. The size of the receptive field was also quantified from the estimated 168 parameter by $1 / \sqrt{\beta}$ which can be regarded as an analog of standard deviation 169 parameter of a normal distribution $(\sigma)$. If the fitting did not converge, the neuron was 170 considered to lack directional selectivity.

171 Once the neuron's preferred direction was determined, we rotated the cue locations 172 so that one of the eight possible locations was placed at the neuron's preferred 173 direction. The monkey then performed randomly intermingled ICT and FCT trials 174 using these rotated cue locations. We only used the data recorded in these 175 post-screening trials with rotated cue locations, except for the estimated receptive field 176 of the neurons which was calculated from the activity during screening ICT trials. The

177 four orthogonal cue locations for the FCT are now referred to as $\mathrm{T}_{\mathrm{in}}, \mathrm{T}_{\mathrm{ipsi}}, \mathrm{T}_{\text {contra }}$ and $178 \mathrm{~T}_{\text {opp }}$; where $\mathrm{T}_{\text {in }}$ is the neuron's preferred direction, $\mathrm{T}_{\text {ipsi }}$ and $\mathrm{T}_{\text {contra }}$ are the 179 perpendicular directions ipsilateral and contralateral to $\mathrm{T}_{\mathrm{in}}$, respectively, and $\mathrm{T}_{\mathrm{opp}}$ is 
180 the opposite direction $180^{\circ}$ away from $\mathrm{T}_{\mathrm{in}}$. The directions other than $\mathrm{T}_{\text {in }}$ (i.e., $\mathrm{T}_{\mathrm{ipsi}}$,

$181 \mathrm{~T}_{\text {contra }}$ and $\mathrm{T}_{\text {opp }}$ ) were also collectively referred to as $\mathrm{T}_{\text {out }}$.

182 Since the focus of the present study was to determine how the spatial 183 representation in the PFC was involved in the animal's own decision-making in 184 choosing saccade directions, we only analyzed FCT trials that included $\mathrm{T}_{\text {in }}$, where the 185 neuron being recorded was responsible to represent, as one of the two cues. Therefore, 186 only three pair conditions $\left(\mathrm{T}_{\text {in }}\right.$ vs $\mathrm{T}_{\text {ipsi }}, \mathrm{T}_{\text {in }}$ vs $\mathrm{T}_{\text {contra }}$, and $\mathrm{T}_{\text {in }}$ vs $\mathrm{T}_{\text {opp }}$ ) out of six

187 possible pair conditions were considered in the present analysis. For the ICT, we only 188 used the data for trials in which the visual cue was presented at one of the four 189 locations appeared in the FCT. Each neuron's directional selectivity was confirmed by 190 a post-recording offline analysis as a larger firing rate in $\mathrm{T}_{\text {in }}$ cue trials than in $\mathrm{T}_{\text {out }}$ cue

191 trials in the ICT with rotated cue locations ( $t$-test, $p<.05)$. Neurons that did not show 192 higher activation in $\mathrm{T}_{\text {in }}$ than in $\mathrm{T}_{\text {out }}$ cue trials in the ICT were excluded from further 193 analysis.

\section{Surgery and Training Procedure}

195 We implanted a stainless steel head-holding device and a scleral search coil in the 196 monkeys. A scleral search coil was implanted onto the right eye globe by dissecting 197 the conjunctiva (Judge et al. 1980). The monkeys were first anesthetized by an 198 intramuscular injection of ketamine hydrochloride $(10 \mathrm{mg} / \mathrm{kg})$ and then an intravenous 199 injection of pentobarbital sodium $(10-15 \mathrm{mg} / \mathrm{kg})$. Heart rate and respiration were 
200 monitored during the surgery. Stainless steel screws were put into the skull to ensure

201 firm adhesion of the head-holding device. The connector for the search coil and the

202 head-holding device were fixed to the skull with dental acrylic. All of the surgical

203 procedures were performed under aseptic conditions.

204 After the monkeys recovered from surgery, we started training of the tasks. We

205 first trained the monkeys with the ICT. When the monkeys learned to perform the ICT

206 (about 85\% correct for more than 5 consecutive experimental sessions), we started to

207 intermingle FCT trials with ICT trials.

208 After we completed the task training, we performed the second surgery to implant

209 a stainless steel cylinder (MO-903E, Narishige, Tokyo) for the recording of neuronal

210 activity. The monkeys were anesthetized with the same procedure as the first surgery

211 and then fixed to the stereotaxic apparatus. We made a small hole (20 $\mathrm{mm}$ in diameter)

212 on the skull with a trephine. The stereotaxic coordination of the center of the hole was

213 set approximately $30.0 \mathrm{~mm}$ anterior from the interaural plane and $15.0 \mathrm{~mm}$ lateral

214 from the midline, and determined by referring structural magnetic resonance imaging

215 (MRI) pictures of the monkey's brain. We attached the stainless steel cylinder to the

216 hole with stainless steel screws and dental acrylic. All of the surgical procedures were

217 performed under aseptic conditions. After the monkeys recovered from surgery, we 218 started neuronal recordings. 


\section{Data Collection}

220 We recorded single-neuron activity from the cortex within and surrounding the

221 principal sulcus. The area of the recording in the lateral PFC was determined based on

222 MRI pictures of the brains. We used glass-coated Elgiloy microelectrodes $(0.5-3.0 \mathrm{M}$

223 at $1 \mathrm{kHz}$ ) to record single-neuron activity. An electrode was advanced with a hydraulic

224 microdrive (MO-95, Narishige, Tokyo). Raw neuronal activity was amplified using an

225 amplifier (DAM80, WPI, Sarasota, FL, USA) and monitored on an oscilloscope

226 (SS-7802, IWATSU, Tokyo) and an audio monitor. During experiments, we isolated

227 single-neuron activity from raw activity using a window discriminator (DIS-1, BAK

228 Electronics, Mount Airy, MD, USA) and monitored the isolated single-neuron activity

229 together with raw activity using an oscilloscope. Single-neuron activity and task events

230 were stored as a data file on a laboratory computer.

\section{Data Analysis}

232 All statistical analyses and data-plotting were performed using the statistical software

233 R 3.2.1 (R Core Team 2015). Before testing the difference in central values among

234 groups, we performed Shapiro-Wilk tests to examine normality of the data in each

235 group. We also performed Bartlett's test or Fligner-Killeen test to examine the

236 homogeneity of variances. Based on the results of these tests, we selected

237 nonparametric test when appropriate. We used Holm's correction method for $p$-values

238 on statistical results taken from a set of multiple comparisons unless otherwise noted. 


\section{Behavioral Analysis}

240 The proportion correct was calculated separately for the ICT and FCT by dividing the

241 number of trials with correct target capture by the number of trials in which the animal 242 reached the response period.

243 To examine the animal's preference toward four directions in the FCT, we defined

244 preference indices based on the proportion of chosen direction. For a given direction,

245 we calculated the proportion of trials in which that direction was chosen by the animal

246 from the total number of trials in which that direction was available in the FCT.

247 Calculated four proportions were then divided by their sum. We call these normalized 248 proportions of choosing each direction as preference indices. Preference index was 249 expected to be 0.25 if the animal chose each direction equally in the FCT. Preference 250 indices were separately calculated for the behavior obtained during recordings of each

251 neuron because the absolute angles of the four directions differed based on the location 252 of the receptive field of neurons.

253 To compare the behaviors in different recording sessions with different cue 254 configurations, we grouped the absolute directions of responses by eight bins of $45^{\circ}$ 255 width. Then we averaged the preference indices categorized into each bin. We used the 256 same bins to calculate averaged response times in the ICT and FCT with different 257 response directions. Response times were measured as the latency from disappearance 258 of the fixation point to the onset of a saccade detected by the method in a previous 259 study (Martinez-Conde et al. 2000). We further tested the animal's task performance in 
260 the FCT based on the relative directions from each neuron's receptive fields. For each

261 of the $\mathrm{T}_{\mathrm{in}}, \mathrm{T}_{\mathrm{ipsi}}, \mathrm{T}_{\text {contra }}$ and $\mathrm{T}_{\text {opp }}$ directions, we calculated the mean response times in

262 correct FCT trials. Response times for these relative directions could vary reflecting

263 the difference in motor execution processes toward different absolute directions.

264 Therefore, for each of the $\mathrm{T}_{\mathrm{in}}, \mathrm{T}_{\mathrm{ipsi}}, \mathrm{T}_{\text {contra }}$ and $\mathrm{T}_{\text {opp }}$ directions, we also calculated the

265 normalized response times by subtracting the mean response time in the ICT from that

266 in the FCT, and then dividing it by the standard deviation of the response times for that

267 direction in the ICT. This tested whether the animal's speed of responses was different

268 among the four response directions in the FCT, cancelling out the effect of the

269 difference in motor processes for different absolute saccade directions.

270 Task-Related Activity and ROC Analysis

271 We used a $100-\mathrm{ms}$ time window sliding in $25-\mathrm{ms}$ steps to make peri-event time

272 histograms to examine task-related activities of the neurons. Constructed histograms

273 were then averaged across neurons to create population histograms. We also used a

274 receiver operating characteristic (ROC) analysis to compare the strength of neuronal

275 activity between two different trial conditions (Britten et al. 1992; Shadlen and

276 Newsome 1996). For each time window, we constructed an ROC curve and calculated

277 the ROC value (area under the ROC curve) using 100 criterion firing rates. To

278 evaluate the onset of ROC elevation, we repeatedly tested the significance of

279 differences in the ROC values of the neurons from 0.5 (one-sample $t$-test, $\alpha=.05$ ). If 
280 the ROC values were larger than 0.5 in five consecutive bins, the time of the first bin 281 was regarded as the onset of ROC elevation.

282 We applied an ROC analysis to the data from both the ICT and FCT. In the ICT, 283 we compared the neuronal firing between $\mathrm{T}_{\text {in }}$ cue trials and $\mathrm{T}_{\text {out }}$ cue trials. Therefore, 284 the calculated ROC value is an index of traditional memory-related activity that 285 encoded the spatial location of the cue instructed in that trial. In the FCT, we 286 compared the neuronal firing between $\mathrm{T}_{\text {in }}$ choice trials and $\mathrm{T}_{\text {out }}$ choice trials in each 287 pair condition. Therefore, the calculated ROC value is an index of decision-related 288 activity that encoded the subsequently chosen spatial location from the same set of 289 cues.

\section{Baseline Sustainability of Firing}

291 Previous studies have suggested that the dynamics of the spontaneous fluctuation in 292 neural activity reflect the background structural and functional architecture of the 293 network (Tsodyks et al. 1999; Kenet et al. 2003). In the present study, we were 294 particularly interested in the relationship between the persistence of spontaneous 295 activity and the neuron's role in memory and decision-making functions. To quantify 296 the persistence of a neuron's activity at a baseline state, we examined the temporal 297 correlation of firing rates within a trial (Ogawa and Komatsu 2010). We divided the 298 first $800 \mathrm{~ms}$ of the pre-cue period (1000-200 ms before cue onset) into eight 299 successive 100-ms time bins. We calculated the trial-to-trial variation in activity within 300 each bin by subtracting the mean firing rate of the given bin across trials from the 
301 firing rate for each trial in the same bin. We then calculated the Pearson's correlation

302 coefficient of these values between two different bins interposed by a given length of

303 interval. Seven intervals (0-600 ms in 100-ms steps) were available depending on the

304 combination of the bins, where "0-ms interval" meant two successive bins and

305 "600-ms interval" meant the longest interval between the first and the last bins of the

306 800-ms period used in this analysis. Different pairs of bins with the same interval were

307 pooled to calculate a single correlation coefficient for each interval length. Therefore,

308 seven correlation coefficients were calculated, one for each of the interval lengths, for

309 each neuron. We refer to the calculated correlation coefficient as "baseline

310 sustainability", since it reflects how the activity within a time bin could be sustained

311 until another temporally distant bin.

\section{Serial Correlation of the Inter-Spike Interval}

313 We also measured the sustainability of the activity of each neuron by calculating a

314 serial correlation of the inter-spike interval (ISI). In this analysis, we first calculated

315 the ISIs of a neuron using all of the collected data including those from non-task

316 epochs such as the inter-trial interval. Next, we calculated Pearson's correlation

317 coefficient between the lengths of successive ISIs. Since the ISI is a measure of the

318 momentary level of activation, a stronger serial correlation of ISI indicates that the

319 activation state once achieved by the neuron tended to persist for a while. 


\section{Dimensional Reduction in Population Activity}

321 We used a dimensional reduction technique with a principal component analysis 322 (PCA) to compare the activation patterns of PFC neurons among different task 323 conditions (Briggman et al. 2005; Broome et al. 2006; Churchland et al. 2007; Shenoy 324 et al. 2013). For each neuron, we first calculated the average firing rate in each task 325 condition (four conditions for the ICT and six conditions for the FCT) during \pm 2000 $326 \mathrm{~ms}$ from the cue onset. We used 50-ms time bins sliding in 25-ms steps to calculate the 327 mean firing rates. We then stacked these averaged firing rates for each neuron and

328 each condition into an $\mathrm{M} \times \mathrm{N}$ matrix, where $\mathrm{M}$ is the number of bins in a trial multiplied 329 by 10 (total number of task conditions) and $\mathrm{N}$ is the number of neurons under interest. 330 We applied a PCA to this matrix. The first three principal components were used to 331 create the principal component state space. The activation state and its transition were 332 represented as a trajectory inside the state space. To evaluate how the neuronal 333 activation patterns differed between the conditions, we calculated the Euclidean 334 distances between trajectories.

\section{Correlation Analysis between Tasks}

336 To investigate how spatial representation was constructed in the network of PFC 337 neurons during an FCT trial, we applied a correlation analysis to the activation patterns 338 of PFC neurons in different tasks. In this analysis, we tested the similarity of the 339 neuronal activation patterns during the FCT to those at the end of the delay period of 340 the ICT. At the end of the delay period in an ICT trial, spatially selective PFC neurons 
341 were expected to represent a sole spatial location to which a saccade was going to be

342 directed soon thereafter. Therefore, the activation pattern of PFC neurons in this period

343 could be regarded as a built template when the network had already finished

344 representing a single spatial location. On the other hand, the pattern of neuronal

345 activation in the cue period of an FCT trial should be more ambiguous because two

346 spatial locations are represented in the network. As the delay period progressed in an

347 FCT trial, the activation pattern should gradually become similar to that in the ICT,

348 since the monkey was required to prepare a saccade toward only one of the two

349 locations. By testing how the neuronal activity was similar between these different

350 periods in different tasks, we tried to examine how the spatial information needed for a

351 subsequent saccade was constructed from the two locations presented in the FCT.

352 For the ICT, we used a 500-ms time bin in a pre-response period ranging from

$353-1000$ to $-500 \mathrm{~ms}$ from the end of the saccade. For the FCT, we used $250-\mathrm{ms}$ time bins

354 sliding through a trial in 1-ms steps. In a given time bin, we first calculated each

355 neuron's average firing rates in each task condition. We then subtracted each neuron's

356 grand average firing rate among task conditions in that bin from its firing rates in each

357 task condition, which gave the discrepancies of each neuron's firing rates in different

358 conditions from its average. Finally, we calculated the rank correlation (Kendall's tau)

359 between each time bin of the FCT and the pre-response period of the ICT between task

360 conditions in which the monkey made the same response (e.g., $\mathrm{T}_{\mathrm{ipsi}}$ cue trials in the

361 ICT and $\mathrm{T}_{\text {out }}$ choice trials in the $\mathrm{T}_{\text {in }}$ vs $\mathrm{T}_{\text {ipsi }}$ pair condition in the FCT). To evaluate 
362 the onset of significant correlation, we tested the significance of the correlation in each

363 bin with $\alpha=.05$. If there was a significant correlation between the FCT and

364 pre-response period activity in the ICT, and if the correlation remained significant

365 until the last time bin of the peri-cue period in the FCT, we regarded the onset of the

366 first bin of these periods as the onset of significant correlation.

367 We also examined the correlation between the activation patterns in $\mathrm{T}_{\text {out }}$ choice

368 trials in the FCT and those in $\mathrm{T}_{\text {in }}$ cue trials in the ICT. These trial conditions differed

369 with respect to the final saccade direction, and thus were expected to result in different

370 activation patterns of directionally selective PFC neurons.

\section{$371 \quad$ Results}

\section{Behavioral Performance}

373 We analyzed the behavioral performance of the animals during the recording sessions.

374 The average proportion of correct performance in the ICT and FCT was $98.0 \%$ and

$37598.3 \%$ for monkey $\mathrm{O}$ and $99.8 \%$ and $99.9 \%$ for monkey E, respectively. There was no

376 statistically significant difference in task performance between the ICT and FCT in

377 either monkey (paired $t$-test, corrected $p=.50$ and .13 ). In correct ICT and FCT trials,

378 the mean response time from the disappearance of the fixation point to the onset of a

379 saccade was $263 \mathrm{~ms}$ and $265 \mathrm{~ms}$ for monkey $\mathrm{O}$ and $231 \mathrm{~ms}$ and $232 \mathrm{~ms}$ for monkey $\mathrm{E}$, 
380 respectively. There was also no significant difference in the response time between the 381 tasks (paired $t$-test, corrected $p=.42$ and .50 ).

382 We further examined the relationship between the animals' behavior and response 383 directions in the tasks. Figure $1 \mathrm{~b}$ shows the response times (lines) and preference 384 indices (bars) for each direction. Two-way ANOVA on each animal's response times 385 revealed a significant main effect of direction (uncorrected $p<.001$ for both monkeys), 386 but there were no main effect of the type of the tasks (uncorrected $p=.12$ and .24 for 387 monkey $\mathrm{O}$ and $\mathrm{E}$, respectively) nor the interaction between task and direction 388 (uncorrected $p=.70$ and .35). In addition, there was no significant effect of direction 389 on the preference indices calculated from the proportion of choices for each direction 390 in the FCT (one-way ANOVA, uncorrected $p=.13$ and .10). Therefore, the observed 391 difference in response times for each direction were more likely to be attributed to the 392 difference in motor execution process rather than the effect of the animal's 393 unequivalent motivation for responses toward each direction.

\section{Neuronal Database}

395 We recorded neurons in and around the principal sulcus during performance of the 396 tasks. Out of 444 neurons recorded, 107 exhibited directionally selective activation 397 during at least one epoch in the screening ICT trials. These neurons were further 398 recorded in randomly intermingled ICT and FCT trials with rotated cue locations (see

399 Tasks in Materials and Methods section). Eighty-four neurons had at least five correct 400 trials for each of the six FCT conditions (three pair conditions $\times$ two choice results) 
401 and were confirmed to have directional selectivity in the post-recording offline 402 analysis. We used these neurons for further analysis. We only used the activity of PFC 403 neurons recorded during intermingled ICT and FCT trials for the analysis below.

404 Based on the rotated cue locations $\left(\mathrm{T}_{\mathrm{in}}, \mathrm{T}_{\mathrm{ipsi}}, \mathrm{T}_{\text {contra }}\right.$ and $\left.\mathrm{T}_{\mathrm{opp}}\right)$ determined by the 405 receptive field of each neuron, we further tested the animals' task performance in the 406 FCT for each direction (Fig. 1c). There was no difference in the proportion of $\mathrm{T}_{\text {in }}$ 407 choice in all the three pair conditions (one-way ANOVA, $p=.11$ ). The proportion of $408 \mathrm{~T}_{\text {in }}$ choice was not significantly different from 0.5 (one-sample Wilcoxon rank sum 409 test, corrected $p>.05$ for all the pair conditions). Also, there was no difference in the 410 response times (one-way ANOVA, $p=.11$ ) and the normalized response times 411 (Kruskal-Wallis test, $p=.11$ ) for each response direction. The normalized response 412 times were not significantly different from 0 (one-sample Wilcoxon rank sum test, 413 corrected $p>.05$ for all the directions), meaning that the responses toward each of the 414 four relative directions in the FCT were comparable to those to the same direction in 415 the ICT. These results indicate that observed characteristics in neuronal activity 416 reported below could not be attributed to the animal's preference toward a particular 417 direction nor to the difference in the degree of motor preparation toward each 418 direction. 


\section{Choice-Predictive Activity}

420 Figure 2 shows the activity of two representative neurons. Both neurons exhibited a

421 larger firing rate in $\mathrm{T}_{\text {in }}$ than in $\mathrm{T}_{\text {out }}$ cue trials $(t$-test, $0-500 \mathrm{~ms}$ from cue onset, $p<.05)$

422 during the cue period of the ICT (top row: ICT trials). Thus, they were more activated

423 during the cue period when the visual cue was presented at $\mathrm{T}_{\text {in }}$. We examined whether

424 the activity of these neurons was related to the monkey's choice in the FCT (bottom

425 three rows: FCT trials for three pair conditions that included $\left.\mathrm{T}_{\mathrm{in}}\right)$. The neuron shown

426 in Fig. 2a exhibited activation in response to the presentation of cues in FCT trials.

427 The magnitude of cue-period activity was almost identical in trials in which the 428 monkey chose $\mathrm{T}_{\text {in }}\left(\mathrm{T}_{\text {in }}\right.$ choice trials $)$ and trials in which the monkey chose $\mathrm{T}_{\text {out }}\left(\mathrm{T}_{\text {out }}\right.$

429 choice trials). This is not surprising because one of the two cues was always presented

430 at the $\mathrm{T}_{\text {in }}$ location (neuron's preferred direction) in all of these three pair conditions.

431 Therefore, this neuron was likely to exhibit a similar magnitude of cue-period activity 432 when the visual cue was presented at $\mathrm{T}_{\text {in }}$ regardless of whether the monkey was going 433 to choose $\mathrm{T}_{\text {in }}$ or $\mathrm{T}_{\text {out }}$ later in that trial.

434 The other neuron in Fig. $2 b$ showed cue-period activity that was related to the 435 animal's subsequent choice in the FCT. In all three pair conditions, the strength of the 436 transient response to the same two cues was significantly different depending on the 437 monkey's subsequent choice. While the neuron was strongly activated during the cue 438 period in $\mathrm{T}_{\text {in }}$ choice trials, this activation was not observed in $\mathrm{T}_{\text {out }}$ choice trials, even 
439 though one of the cues was simultaneously presented at $\mathrm{T}_{\text {in }}\left(t\right.$-test between $\mathrm{T}_{\text {in }}$ and

$440 \mathrm{~T}_{\text {out }}$ choice trials, $0-500 \mathrm{~ms}$ from cue onset, $p<.05$, pair conditions collapsed). We

441 refer to this firing pattern of PFC neurons (i.e., strong activation in $\mathrm{T}_{\text {in }}$ choice trials

442 compared to $\mathrm{T}_{\text {out }}$ choice trials in the FCT) as "choice-predictive". In every FCT trial

443 with a given pair condition, the monkey was presented with two physically identical

444 cues at the same spatial locations regardless of which of them was chosen later in that

445 trial. Therefore, choice-predictive activity can not be explained as a mere reflection of

446 the physical stimuli. Rather, the strong correlation between neuronal activity and the

447 animal's subsequent choice suggests that PFC neurons play an active role in the free

448 choice of a spatial location. Choice-predictive activity was also observed in the

449 pre-cue period (Fig. 2b). The activity of the neuron was slightly, but significantly,

450 higher before the start of the cue period when the monkey was going to choose the

451 neuron's preferred direction in the current trial ( $t$-test between between $\mathrm{T}_{\text {in }}$ and $\mathrm{T}_{\text {out }}$

452 choice trials, $1000-0 \mathrm{~ms}$ before cue onset, $p<.05$, pair conditions collapsed).

453 Population Activity

454 We confirmed the presence of choice-predictive activity in the cue and pre-cue periods 455 of the FCT in a population analysis. Figure 3 shows population histograms and ROC 456 transition of 59 PFC neurons that exhibited directionally selective cue-period activity. 457 Differential firing in response to the cues presented in the FCT was consistently 458 observed between $\mathrm{T}_{\text {in }}$ choice trials and $\mathrm{T}_{\text {out }}$ choice trials (Fig. $3 \mathrm{~b}$ ). We analyzed the 
459 activity of these neurons during the cue period in each task condition (0-500 ms from 460 cue onset). In the ICT, cue-period activity in $T_{\text {in }}$ trials (average 20.2 spikes/s) was 461 significantly stronger than that in $\mathrm{T}_{\text {ipsi }}(12.0$ spikes/s $), \mathrm{T}_{\text {contra }}(11.6 \mathrm{spikes} / \mathrm{s})$ and $\mathrm{T}_{\text {opp }}$ 462 (9.8 spikes/s) trials (paired $t$-test, corrected $p<.001$ for all comparisons). In the FCT, 463 cue-period activity in $\mathrm{T}_{\text {in }}$ choice trials was also significantly stronger than that in $\mathrm{T}_{\text {out }}$ 464 choice trials in all three pair conditions (corrected $p<.001$ for all pair conditions). In 465 comparisons of different FCT pair conditions, the activity in $\mathrm{T}_{\text {in }}$ choice trials were 466 comparable among the $\mathrm{T}_{\text {in }}$ vs $\mathrm{T}_{\text {ipsi }}\left(19.4\right.$ spikes/s), $\mathrm{T}_{\text {in }}$ vs $\mathrm{T}_{\text {contra }}(20.2$ spikes/s $)$ and $467 \mathrm{~T}_{\text {in }}$ vs $\mathrm{T}_{\text {opp }}(20.6 \mathrm{spikes} / \mathrm{s})$ pair conditions (corrected $p=.94, .89$ and .94 , respectively). 468 However, in the $\mathrm{T}_{\text {out }}$ choice trials, neurons tended to be more activated in the $\mathrm{T}_{\text {in }} \mathrm{vs}$ $469 \mathrm{~T}_{\text {ipsi }}$ pair condition (16.9 spikes/s) than in the $\mathrm{T}_{\text {in }}$ vs $\mathrm{T}_{\text {contra }}(14.9$ spikes/s, corrected $470 p=.060)$ and $\mathrm{T}_{\text {in }}$ vs $\mathrm{T}_{\text {opp }}(14.9$ spikes/s, corrected $p=.065)$ pair conditions, while there 471 was no significant difference between the latter two pair conditions (corrected $p=.97$ ).

472 We also performed an ROC analysis on the cue-period activity of these neurons in $473 \mathrm{~T}_{\text {in }}$ and $\mathrm{T}_{\text {out }}$ choice trials in the FCT. In all the three pair conditions, average ROC 474 values $(0.57,0.61$ and 0.63 for each of the three pair condition) were all significantly 475 larger than 0.5 (one-sample $t$-tests, corrected $p<.001$ for all of the conditions) in the 476 cue period (0-500 ms from cue onset). By examining the change in the ROC value 477 throughout the entire trial epoch using a sliding window, we observed early elevation 478 of the ROC value that started before the presentation of the cues (Fig. 3d). A 
479 significant increase in the ROC value from 0.5 was observed 750 ms before the onset

480 of the cues. The same analysis of activation during the ICT revealed that an elevation

481 of the ROC value (calculated between the $\mathrm{T}_{\text {in }}$ and $\mathrm{T}_{\text {out }}$ cue trials) was observed 150

$482 \mathrm{~ms}$ after the onset of the cue when the direction of the saccade was instructed (Fig. 3c).

483 These results indicate that the choice-predictive activity of PFC neurons in the pre-cue

484 period of the FCT was not an artifact of the task structure, but rather reflected the

485 influence of these neurons on the animal's decision-making regarding the saccade

486 direction when the choice was left to the animal.

487 Relationship between Choice-Predictive Activity and

488 Persistent Delay-Period Activity

489 To further investigate the role of PFC neurons in the decision-making regarding the

490 saccade direction, we compared the activities and firing properties of neurons with and

491 without choice-predictive activity in the FCT. We categorized a neuron as

492 choice-predictive if it exhibited a differential activation between the $T_{\text {in }}$ and $T_{\text {out }}$

493 choice trials during the cue and pre-cue periods (-1000 to $500 \mathrm{~ms}$ from cue onset) in at

494 least one of the three FCT pair conditions ( $t$-test). Figure 4 shows population

495 histograms of neurons with and without choice-predictive activity. PFC neurons with

496 choice-predictive activity also showed directionally selective persistent delay-period

497 activity. On the other hand, neurons without choice-predictive activity were activated

498 only during cue presentation, and did not exhibit persistent delay-period activity. 
Based on this difference in task-related activity between neurons with and without

500 choice-predictive activity, we further compared these two groups in terms of the 501 persistence of activation (Fig. 5). We first quantified the strength of directionally 502 selective persistent activity during the delay period of the ICT for each neuron by 503 calculating the ROC value between $T_{\text {in }}$ and $T_{\text {out }}$ cue trials at the middle of the delay 504 (1000-1500 ms from the start of the delay period of the ICT). When compared among 505 all of the directionally selective neurons (Fig. 5a, $n=84$ ), the strength of directionally 506 selective persistent activity in the ICT was closely correlated (Pearson's $R=.345$, $507 p<.001)$ with the strength of the choice-predictive difference in activity in the cue and 508 pre-cue periods of the FCT (quantified by the ROC value calculated between $\mathrm{T}_{\text {in }}$ and $509 \mathrm{~T}_{\text {out }}$ trials within -1000 to $500 \mathrm{~ms}$ from cue onset, pair conditions collapsed). When 510 compared between groups, choice-predictive neurons had stronger directional 511 selectivity in the delay period in the ICT than choice-unpredictive neurons (Fig. 5c, 512 Wilcoxon rank sum test, $p<.001$ ). In addition, the choice-predictive neurons showed a 513 higher baseline sustainability of activation even in the pre-cue period (Fig. $5 \mathrm{~d}, t$-test, $514 p<.05$ ) and a stronger serial correlation of the ISI (Fig. 5e, Wilcoxon rank sum test, $515 p<.05)$. Choice-predictive neurons were characterized by a higher sustainability of 516 activation even between temporally distant time bins (Fig. 5b). The persistence of 517 activation as measured by the baseline sustainability and the serial correlation of the 518 ISI could be important for retention of the spatial information as sustained firing 519 during the delay, and thus can be regarded as a key feature of PFC neurons in spatial 
520 working memory function. The coupling of these measures to the presence of 521 choice-predictive activity in the early task epochs of the FCT suggests that the firing 522 properties of PFC neurons that are essential to the memory function might also lead to 523 a distinctive role of these neurons in the selection of spatial locations in a free-choice 524 condition.

525 We examined the possible effect of behavioral difference as well as the difference 526 in receptive field properties between choice-predictive and unpredictive neurons. 527 However, there were no difference between the two groups of neurons in the 528 distribution of the preferred directions (Fig. 5f, Watson's test for homogeneity of 529 circular data, $p>.10$ ) nor the size of the receptive fields (Fig. 5g, Wilcoxon rank sum 530 test, $p=.21$ ). Also, two-way ANOVA on the proportion of $\mathrm{T}_{\text {in }}$ choices revealed no 531 main effects of neuron groups (choice-predictive/unpredictive neurons) and pair 532 conditions, nor the interaction of these two factors (Fig. 5h, $p>.05$ for both main 533 effects and the interaction). One-sample $t$-tests revealed that the proportion of $\mathrm{T}_{\text {in }}$ 534 choices was not significantly different from 0.5 in any of the neuron groups and pair 535 conditions (corrected $p>.05$ for all the $2 \times 3$ combinations of neuron groups and pair 536 conditions). The same comparison on the difference of the response times between $\mathrm{T}_{\text {in }}$ 537 choice and $\mathrm{T}_{\text {out }}$ choice trials also revealed no significant main effects nor interaction 538 of neuron groups and pair conditions (Fig. 5i, $p>.05$ for both main effects and the 539 interaction). One-sample $t$-tests revealed that the difference of the response times 540 between $\mathrm{T}_{\text {in }}$ choice and $\mathrm{T}_{\text {out }}$ choice trials was not significantly different from zero in 
541 any of the neuron groups and pair conditions (corrected $p>.05$ for all the 542 combinations).

543 Comparison of the Neuronal Activation Pattern in a State

\section{Space}

545 To gain further insight into how spatial representations are held and integrated in the 546 network of the PFC to perform a final saccadic response in the FCT, we used a 547 dimensional reduction technique. The change in neuronal activation in each task 548 condition in the ICT and FCT was expressed as a trajectory in a principle component 549 state space (Fig. 6). In the ICT (Fig. 6a), the four trajectories that represented the 550 neuronal activation patterns in $\mathrm{T}_{\mathrm{in}}, \mathrm{T}_{\mathrm{ipsi}}, \mathrm{T}_{\text {contra }}$ and $\mathrm{T}_{\text {opp }}$ cue trials remained within 551 the neighboring area until the time of cue onset. The trajectory for $\mathrm{T}_{\text {in }}$ cue trials then

552 started to diverge from those for the other three cue conditions, which reflected a 553 strong transient activity of directionally selective neurons in response to cue 554 presentation (Fig. 3a). In the FCT (Fig. 6b), the trajectories for $\mathrm{T}_{\text {in }}$ choice and $\mathrm{T}_{\text {out }}$ 555 choice trials reached slightly distant points in the space even at the beginning of the 556 cue period. After the presentation of the cues, the trajectories for $\mathrm{T}_{\text {in }}$ choice trials 557 further deviated from those for $\mathrm{T}_{\text {out }}$ choice trials and tracked similar paths to the 558 trajectory for $\mathrm{T}_{\text {in }}$ cue trials in the ICT. Conversely, the trajectories for $\mathrm{T}_{\text {out }}$ choice 
559 trials returned to the initial state during the cue and delay periods, in a similar manner 560 to $\mathrm{T}_{\text {out }}$ cue trials in the ICT.

561 However, in the $\mathrm{T}_{\text {in }}$ vs $\mathrm{T}_{\text {ipsi }}$ pair condition, the trajectory for $\mathrm{T}_{\text {out }}$ choice trials 562 remained relatively adjacent to that for $T_{\text {in }}$ choice trials, compared to the other two 563 pair conditions. To evaluate the difference in neuronal activation patterns, we 564 calculated the distance between the trajectories for the $\mathrm{T}_{\text {in }}$ choice and $\mathrm{T}_{\text {out }}$ choice trials 565 in each of the three pair conditions in the FCT (Fig. 6c). In the $\mathrm{T}_{\text {in }} \mathrm{vs} \mathrm{T}_{\text {contra }}$ and $\mathrm{T}_{\text {in }}$ 566 vs $\mathrm{T}_{\text {opp }}$ pair conditions, the distance between the trajectories for $\mathrm{T}_{\text {in }}$ choice and $\mathrm{T}_{\text {out }}$ 567 choice trials increased in the cue period. In the $\mathrm{T}_{\text {in }} \mathrm{vs}_{\mathrm{ipsi}}$ pair condition, the distance 568 between $\mathrm{T}_{\text {in }}$ and $\mathrm{T}_{\text {out }}$ choice trials remained relatively small in the cue period and 569 gradually increased during the delay period. The average distance between $\mathrm{T}_{\text {in }}$ and $570 \mathrm{~T}_{\text {out }}$ trajectories during the cue period was $24.7,66.5$ and 72.8 for the $\mathrm{T}_{\text {in }} \mathrm{vs}_{\mathrm{ipsi}}, \mathrm{T}_{\text {in }}$ 571 vs $\mathrm{T}_{\text {contra }}$, and $\mathrm{T}_{\text {in }}$ vs $\mathrm{T}_{\text {opp }}$ pair conditions, respectively. Paired $t$-tests revealed that 572 there was a significantly less distance between the trajectories for $\mathrm{T}_{\text {in }}$ and $\mathrm{T}_{\text {out }}$ choice 573 trials in the $\mathrm{T}_{\text {in }}$ vs $\mathrm{T}_{\text {ipsi }}$ pair condition than in the other two pair conditions (corrected $574 p<.001$ ). The distance between the $\mathrm{T}_{\text {in }}$ and $\mathrm{T}_{\text {out }}$ trajectories was also greater in the $\mathrm{T}_{\text {in }}$ 575 vs $\mathrm{T}_{\text {opp }}$ pair condition than in the $\mathrm{T}_{\text {in }}$ vs $\mathrm{T}_{\text {contra }}$ condition (paired $t$-test, corrected $576 p<.001)$, but this difference was small. These results support the observation in the 577 population histograms and ROC analysis that choice-predictive activity was 
578 established more slowly when the two cues were presented in the same hemifield $\left(\mathrm{T}_{\text {in }}\right.$

$579 \quad$ vs $\mathrm{T}_{\text {ipsi }}$ pair condition).

\section{Effect of Cue Configuration}

581 Previous analyses suggested that the time course of the establishment of 582 choice-predictive activity was dependent on the configuration of the cues. To 583 investigate how the final spatial representation was constructed in each pair condition 584 of the FCT, we used a between-task correlation analysis on the firing patterns of 585 directionally selective PFC neurons. In this analysis, we examined the correlation of 586 neuronal activity between the FCT and the pre-response period of the ICT. For each 587 task condition and each time bin in the FCT, we calculated the correlation coefficient 588 between the activation of directionally selective PFC neurons $(n=84)$ in that time bin 589 and that in the pre-response period (1000-500 ms before the end of the saccade) of the

590 ICT. As the decision-making process regarding the subsequent saccade direction 591 progressed in the FCT, the correlation coefficient was expected to increase because the 592 activation pattern of PFC neurons should have been similar to that when the animal 593 was ready to make a saccade in the ICT. By measuring the transition of correlation 594 coefficients in each task condition, we tried to clarify how the configuration of the 595 cues might influence the dynamics of visuospatial decision-making in FCT trials.

596 Figure 7 shows the correlation in the neuronal activation pattern between the FCT 597 and the pre-response period of the ICT. We first examined the correlation between the 
598 ICT and FCT in which the monkey eventually made a response to the same direction

599 (correlation between $\mathrm{T}_{\text {in }}$ cue/choice trials for Fig. 7a, $\mathrm{T}_{\text {out }}$ cue/choice trials for Fig. $7 \mathrm{~b}$ ).

600 In the $\mathrm{T}_{\text {in }} \mathrm{vs} \mathrm{T}_{\text {contra }}$ and $\mathrm{T}_{\text {in }}$ vs $\mathrm{T}_{\text {opp }}$ pair conditions, the correlation coefficients started

601 to rise from zero at around the beginning of the cue period. In the $\mathrm{T}_{\text {in }} \mathrm{vs}_{\mathrm{T}}$ contra pair

602 condition, a significant correlation started to be observed $142 \mathrm{~ms}$ before the start of the

603 cue period in $\mathrm{T}_{\text {in }}$ choice trials, and $48 \mathrm{~ms}$ after cue onset in $\mathrm{T}_{\text {out }}$ choice trials. In the

$604 \mathrm{~T}_{\text {in }} \mathrm{vs} \mathrm{T}_{\text {opp }}$ pair condition, a significant correlation started to be observed $90 \mathrm{~ms}$ before

605 and $113 \mathrm{~ms}$ after cue onset in $\mathrm{T}_{\text {in }}$ choice and $\mathrm{T}_{\text {out }}$ choice trials, respectively. However,

606 in the $T_{\text {in }}$ vs $T_{\text {ipsi }}$ pair condition, the development of a correlated activation pattern

607 was weak. In $\mathrm{T}_{\text {in }}$ choice trials, the onset of significant correlation was $408 \mathrm{~ms}$ after cue

608 presentation. In $\mathrm{T}_{\text {out }}$ choice trials, significant correlation that lasted stably during the

609 delay period was not observed. This result indicates that, in the network of spatially

610 selective PFC neurons, a sole spatial representation was constructed from the

611 presented two locations more slowly when the two cues were located in the same

612 hemifield, consistent with the observation in the previous analyses on population

613 activity (Fig. 3d) and the neuronal state space (Fig. 6c). Especially, the slower

614 development of choice-predictive activity in the $T_{\text {in }}$ vs $T_{\text {ipsi }}$ pair condition may be the

615 result of the disarranged construction of spatial representation in $\mathrm{T}_{\text {out }}$ choice trials in 616 this pair condition. 
617 For $\mathrm{T}_{\text {out }}$ choice trials in the FCT, we also examined the correlation of the neuronal 618 activation pattern with that in $\mathrm{T}_{\text {in }}$ cue trials in the ICT (Fig. 7c). In all three pair 619 conditions of the FCT, $\mathrm{T}_{\text {in }}$ cue was presented during the cue period. However, since 620 the final saccade directions were not in the neurons' receptive fields in $\mathrm{T}_{\text {out }}$ choice 621 trials, the activity of PFC neurons were expected to gradually become different 622 compared to when $\mathrm{T}_{\text {in }}$ was instructed in the ICT. We confirmed this prediction as an 623 early negative correlation of the neuronal activation patterns in the $T_{\text {in }} v \mathrm{~T}_{\text {contra }}$ and $624 \mathrm{~T}_{\text {in }}$ vs $\mathrm{T}_{\text {opp }}$ pair conditions. In $\mathrm{T}_{\text {out }}$ choice trials, the population activity of PFC 625 neurons started to differ from that in $\mathrm{T}_{\text {in }}$ cue trials in the ICT at $296 \mathrm{~ms}$ and $158 \mathrm{~ms}$ 626 before the onset of the cues in the $T_{\text {in }}$ vs $T_{\text {contra }}$ and $T_{\text {in }}$ vs $T_{\text {opp }}$ pair conditions, 627 respectively. In contrast, the onset of a significant negative correlation was $941 \mathrm{~ms}$ 628 after cue onset (441 ms after the start of the delay period) in the $T_{\text {in }} v \mathrm{~V}_{\text {ipsi }}$ pair 629 condition. This means that the activation state of PFC neurons in $\mathrm{T}_{\text {out }}$ choice trials in 630 the $\mathrm{T}_{\text {in }}$ vs $\mathrm{T}_{\text {ipsi }}$ pair condition remained indistinguishable from that in $\mathrm{T}_{\text {in }}$ cue trials in 631 the ICT for a longer period. This result also suggested that the construction of spatial 632 representation for $\mathrm{T}_{\text {out }}$ was slower in the $\mathrm{T}_{\text {in }} \mathrm{vs} \mathrm{T}_{\mathrm{ipsi}}$ pair condition than in the other 633 pair conditions. 


\section{Discussion}

635 In the present study, we investigated the role of spatially selective PFC neurons in

636 animal's decision about saccade direction in a free choice condition. When $\mathrm{T}_{\text {in }}$ was

637 later chosen as a saccade direction, PFC neurons were strongly activated by cue

638 presentation despite the presence of another cue outside their preferred direction.

639 Choice-predictive activity was distinct from the very beginning of the cue period and

640 was observed even before cue onset.

641 The positive correlation between the strength of the delay-period activity in the

642 ICT (memory-related activity) and the strength of the choice-predictive activity in the

643 cue and pre-cue periods of the FCT (decision-related activity) revealed that PFC

644 neurons with stronger memory-related activity in the ICT tended to show stronger

645 choice-predictive activity in the peri-cue periods of the FCT. The stronger

646 sustainability of firing in neurons with choice-predictive activity suggested that

647 memory and decision functions are supported by a common feature of PFC neurons to

648 sustain their activation state within the circuitry. In addition, when to-be-chosen $\mathrm{T}_{\text {out }}$

649 was located in a hemifield different from that in which $\mathrm{T}_{\text {in }}$ was located, the transient

650 response to cue presentation was weak. However, when to-be-chosen $\mathrm{T}_{\text {out }}$ was in the

651 same hemifield as $\mathrm{T}_{\text {in }}$, the cue-period activity was stronger, even though the neuron's

652 preferred direction was not going to be chosen. This indicates that unnecessary spatial

653 information tended to be suppressed from the beginning of its representation in the 
654 PFC, but this adaptive modulation was modest if the two spatial locations were in the

655 same hemifield. Our present study revealed that the role of the PFC in 656 decision-making process is closely linked to its role in information maintenance 657 process, and these different processes share the same functional characteristics that 658 emerged from the underlying cellular mechanism.

\section{Activity of PFC Neurons Related to the Animal's Decision}

660 In the present study, we found that the strength of neurons' activity in pre-cue and cue 661 periods was correlated with the animal's subsequent decision regarding the saccade 662 direction (choice-predictive activity). However, in the FCT, one of the six pair 663 conditions was randomly assigned in each trial. Also, FCT trials were randomly 664 intermingled with ICT trials. Only after cue presentation could the animal know 665 whether they were allowed to choose the saccade direction by themselves or where the 666 options for the choice would be. Therefore, it was impossible for the animal to make a 667 reasonable decision before cue onset. We propose that this early choice-predictive 668 activity can be explained as an influence of fluctuating neuronal firing before the start 669 of a trial. In each trial, the activity of directionally selective neurons can randomly 670 fluctuate during the pre-cue period. This fluctuation of activity can be regarded as

671 baseline random noise in spatial representation in the PFC. If the activity of neurons 672 that are responsible for a particular direction happen to be elevated during the pre-cue 673 period of an FCT trial, these neurons should be able to more quickly respond to the 674 presentation of cues one of which appeared at their preferred direction. In the network 
675 of the PFC, neurons responsible to different spatial locations have inhibitory 676 connections, so that the PFC retains only the most relevant spatial information in a 677 winner-take-all manner (Rao et al. 1999; Compte et al. 2000; Wang et al. 2004). 678 Therefore, the faster construction of a spatial representation will disturb the formation 679 of other spatial representations through mutual competition, resulting in the adoption 680 of the prematurely biased location as the direction of the saccade in the current trial. 681 As a result, trials in which directionally selective PFC neurons show slightly stronger 682 activation before the cue period should be over-represented among trials in which their 683 preferred direction was later chosen by the animal.

684 Previous studies have reported the activity of neurons in the PFC, frontal eye field, 685 supplemental eye field and lateral intraparietal cortex using memory-guided 686 (Watanabe et al. 2006; Watanabe and Funahashi 2007) or visually guided (Coe et al. 687 2002) free choice tasks. However, in these studies, a same set of fixed locations were 688 repeatedly presented in a block of trials. Therefore, a detailed investigation of the time 689 course of neuronal activity and the interpretation of its role in decision-making were 690 difficult since the animal could easily predict the available options independently of 691 the progress of a trial. Also, in those task setups, the animal could exhibit a strong 692 tendency or strategy to repeatedly choose the same option. Therefore, the previous 693 studies used particular reinforcement rules to prohibit the animal from choosing the 694 same option repeatedly, and forced the animal to choose different options. This 695 procedure can be regarded as a trained allocation of choices administrated by a reward 
696 schedule. In the present study, we intermingled ICT and FCT trials and changed the 697 combination of the options for a decision. In addition, the absolute locations of the

698 four options changed randomly for the animal depending on the receptive field of the

699 neuron. As a result, the monkeys were presented with different decision contexts from

700 trial to trial, and their choices were substantially varied among options without

701 restrictive rules for decision. We propose that our current experimental design is more 702 appropriate for the investigation of the neuronal mechanisms of internally driven 703 decision-making compared to the previous studies.

704 In other cortical areas, a biasing effect of baseline fluctuation of the neuronal 705 activity on the subsequent animal's behavior has been reported (Platt and Glimcher 706 1999; Shadlen and Newsome 2001). For example, Shadlen and Newsome (2001)

707 reported that the activity of primate lateral intraparietal neurons before the onset of 708 random-dot motion stimulus was higher when motion coherency was weak and the 709 neurons' preferred motion direction was going to be chosen. They argued that this was

710 because the existing neuronal fluctuation before stimulus presentation biased the 711 subsequent competition between the representations of different motion directions. 712 Rolls and Deco (2011) recently reported that this kind of bias based on random 713 fluctuation could actually take place in an integrate-and-fire attractor network model. 714 They confirmed the relationship between pre-existing random fluctuation in 715 spontaneous activity and the result of the subsequent neuronal competition in an 716 artificial network in which there was no potential confounding such as a subject's 
717 specific behavioral strategies. Our present results are in accord with these previous 718 reports.

\section{Relationship between Decision-Making and Memory}

\section{Maintenance}

721 We found that neurons with choice-predictive activity during cue and pre-cue periods

722 showed higher sustainability of firing such as an elevated delay-period activity (Fig. 4

723 and 5). The persistent delay-period activity of PFC neurons while the monkey is

724 remembering a particular spatial location is thought to be the neural basis of spatial

725 working memory (Funahashi et al. 1989, 1990; Goldman-Rakic et al. 1990; Miller and

726 Cohen 2001; Fuster 2008). An elevated firing rate sustained during several seconds of

727 delay is not likely to be supported only by subcellular mechanisms, and is instead

728 attributed to the network property of the PFC with recurrent feedback inputs

729 (Constantinidis and Wang 2004; Wang 2013). We propose that the strong correlation

730 between memory-related activity (persistent delay-period activity in the ICT) and

731 decision-related activity (choice-predictive activity in the FCT) is a consequence of

732 this network property of the PFC. Since PFC neurons are mutually interconnected, the

733 incidental activation of a group of neurons before the start of a trial could persist for

734 some time through this network. Heterogeneity in the activation level among neurons

735 might further be amplified during the pre-cue period through mutual facilitation and

736 competitive inhibition of neurons with the same and different directional selectivities, 
737 respectively. The premature imbalance of activation will then result in a difference in

738 the strength of cue representations in the cue period and the animal's final choice

739 toward the strongly represented direction in the FCT.

740 In recent electrophysiological research, there has been a debate about the role of

741 the lateral PFC in spatial information processing. Several studies have proposed that

742 lateral PFC is more related to the spatial attention than spatial working memory

743 (Lebedev et al. 2004; Messinger et al. 2009; Everling et al. 2002; DeSouza and

744 Everling 2004; Lennert and Martinez-Trujillo 2011, 2013; Tremblay et al. 2015). For

745 instance, by using a behavioral task in which a location to remember and a location to

746 allocate a visually-guided attention are separated, Lebedev et al. (2004) showed that

747 large proportion of lateral PFC neurons are selective to attended rather than

748 remembered spatial location. In their study, spatial working memory process was

749 depicted as maintenance memory, and separated from attention process by preventing

750 the animal from paying attention to the remembered location. However, the concept of

751 working memory includes both active maintenance and manipulation of information

752 (Baddeley and Hitch 1974; Baddeley 1986, 2003). Working memory tasks in animals

753 (Dudchenko 2004) and humans (Miyake et al. 2000) typically consist of attentional

754 shifting, updating or inhibitory control of the maintained information. This is because

755 a mere maintenance of information is unlikely in a variety of cognitive operations, and

756 the maintenance of task-relevant information necessarily requires attentional control.

757 This joint formularization of memory and attention is the essence of the working 
758 memory, and the validity of working memory concept in clinical, developmental and

759 experimental psychology (Baddeley 2003; Saperstein et al. 2006; Conway et al. 2003;

760 Kane and Engle 2003) suggests that maintenance and attentional manipulation of

761 information can not be dissociated as independent processes.

762 Based on these psychological backgrounds, the elucidation of how maintenance

763 and manipulation of information are simultaneously and jointly performed in the

764 activity of cortical neurons is essential for the understanding of the neuronal

765 mechanism of working memory. Therefore, in the present study, we used a traditional

766 memory-guided saccade task combined with subjective decision-making process. As a

767 result, we observed that fluctuation of the activity of PFC neurons before cue

768 presentation induced an early bias in the representation of spatial cues, and eventually

769 influenced the animal's decision. Importantly, this task-related activity was correlated

770 with more fundamental firing characteristic of PFC neurons to sustain its activation

771 state for relatively longer period. If there is no such persistence in neuronal activity,

772 the premature fluctuation of activity before a trial could not survive until presentation

773 of the cues and should never influence the animal's behavior. In this sense, the

774 capability of the PFC network to maintain spatial information played a pivotal role in

775 the decision-making process under a free-choice condition. This is a succinct example

776 that the network property of the PFC that enables the maintenance of information can

777 be regarded as a key feature in understanding the PFC's roles in other cognitive

778 processes (Procyk and Goldman-Rakic 2006; Wang 2008). Especially, the effect of 
779 pre-existing neural state on subsequent decision-making is a prevailing subject in

780 recent noninvasive electrophysiological studies in human (Hesselmann et al. 2008;

781 Bode et al. 2012; Bengson et al. 2014). Our present report directly demonstrated the

782 neuronal underpinning of such phenomena from the viewpoint of the known function

783 and characteristics of PFC neuron's activity, and also showed that the influence of

784 pre-existing fluctuation takes place in the order of hundreds milliseconds in

785 task-related neuronal activity. Our report provides a clue for integrated understanding

786 of lateral PFC's role in spatial decision-making and working memory functions, from

787 a viewpoint of basic characteristics of neuronal firing in this cortical area.

788 Competition of Spatial Representations Within or Between

789 Hemifields

790 In previous studies regarding the role of the PFC in working memory function, a single

791 visual cue has been used to inform the animals of the location to be remembered for an

792 upcoming saccade (Boch and Goldberg 1989; Funahashi et al. 1989, 1990; Rainer et al.

793 1998). In these studies, PFC neurons with mnemonic visuospatial activity tended to

794 have directional selectivity toward locations contralateral to the side of the hemisphere

795 being recorded. A unilateral lesion to the PFC was reported to result in disrupted

796 performance of the memory-guided saccade to the contralateral hemifield (Funahashi

797 et al. 1993a). These findings suggest that the PFC is organized to participate in the

798 processing of spatial information in the contralateral hemifield (Funahashi 2013). 
The activity of PFC neurons during the performance of a memory-guided saccade

800 task in which the monkeys chose the saccade direction by themselves has been

801 previously reported (Watanabe et al. 2006; Watanabe and Funahashi 2007). However,

802 in those experiments, the locations of the cues were fixed to the four perpendicular

803 directions and all the four cues were repeatedly presented in a block of trials.

804 Therefore, the influence of contralateral organization of the PFC on the representation

805 of multiple pieces of spatial information could not be examined. In the present study,

806 we compared the time course of the emergence of choice-predictive activation among

807 the three FCT pair conditions. We found that choice-predictive activity developed

808 more slowly in the $\mathrm{T}_{\text {in }} \mathrm{vs} \mathrm{T}_{\text {ipsi }}$ pair condition than in the $\mathrm{T}_{\text {in }} \mathrm{Vs} \mathrm{T}_{\text {contra }} / \mathrm{T}_{\text {opp }}$ conditions

809 (Fig. 6). The slow construction of the final spatial representation was especially

810 obvious in $\mathrm{T}_{\text {out }}$ choice trials in the $\mathrm{T}_{\text {in }} \mathrm{vs} \mathrm{T}_{\text {ipsi }}$ pair condition (Fig. 7). We propose that

811 this stronger representation of the unchosen direction when the two cues are located in

812 the same hemifield is the result of the contralateral organization of the PFC. Since

813 neurons with directional selectivity toward a particular side of the visual space are

814 assembled in the contralateral hemisphere of the PFC, they may be more tightly

815 interconnected through local circuits than neurons with preferences for different

816 hemifields, which are more likely to be distributed in different hemispheres and thus

817 require callosal connections to interact with each other. A recent study on the

818 concurrent memorization of multiple spatial locations has also suggested a stronger

819 interaction between spatial representations within the same hemifield (Matsushima and 
820 Tanaka 2014). Through this stronger local connection, the spontaneous fluctuation of

821 neuronal activity can be more frequently shared by neurons with a preference for the

822 same hemifield. The shared fluctuation between neurons before the start of a trial can

823 be regarded as unbiased pre-existing spatial representation, which leads to strong

824 representations of both subsequently chosen and unchosen locations in response to the

825 presented cues. In contrast, the pre-existing activation levels may vary between

826 neurons with preferences for locations in different hemifields, which can then cause

827 suppression of the representation of the subsequently unchosen location by amplifying

828 the premature bias. Therefore, the difference in the time course of the development of

829 choice-predictive activity among pair conditions can be explained by uneven

830 lateralization of directionally selective neurons in the PFC. Future studies with

831 simultaneous recordings of PFC neurons are needed for quantitative investigation of

832 correlated fluctuation in the spontaneous activity of spatially selective neurons.

\section{Grants}

834 This research was supported by Grants-in-Aid for Scientific Research (21240024 and 835 25240021) from the Ministry of Education, Culture, Sports, Science and Technology

836 (MEXT) of Japan to S. F., and by a Grant-in-Aid for JSPS Fellows (23.7155) from the

837 Japan Society for the Promotion of Science to K. M. The animals were provided by the

838 National BioResource Project "Japanese Monkeys" supported by the MEXT, Japan. 


\section{Disclosures}

840 There are no competing financial interests.

841 


\section{References}

843 Baddeley A. Working Memory. Oxford, UK: Oxford University Press, 1986.

844 Baddeley A. Working memory: looking back and looking forward. Nat Rev Neurosci 4: 829-839, 2003.

845 Baddeley AD, Hitch G. Working memory. In: Recent Advances in Learning and Motivation., edited by Bower GH, New York: Academic Press, 1974, volume 8 of Psychology of Learning and Motivation, pp. 47-89.

848

Bengson JJ, Kelley TA, Zhang X, Wang JL, Mangun GR. Spontaneous neural fluctuations predict decisions to attend. J Cogn Neurosci 26: 2578-2584, 2014.

Boch RA, Goldberg ME. Participation of prefrontal neurons in the preparation of visually guided eye movements in the rhesus monkey. J Neurophysiol 61: 1064-1084, 1989.

Bode S, Sewell DK, Lilburn S, Forte JD, Smith PL, Stahl J. Predicting perceptual decision biases from early brain activity. J Neurosci 32: 12488-12498, 2012.

Briggman KL, Abarbanel HDI, Kristan WB. Optical imaging of neuronal populations during decision-making. Science 307: 896-901, 2005.

Britten KH, Shadlen MN, Newsome WT, Movshon JA. The analysis of visual motion: a comparison of neuronal and psychophysical performance. J Neurosci 12: 4745-4765, 1992.

Broome BM, Jayaraman V, Laurent G. Encoding and decoding of overlapping odor sequences. Neuron 51: 467-482, 2006.

Churchland MM, Yu BM, Sahani M, Shenoy KV. Techniques for extracting single-trial activity patterns from large-scale neural recordings. Curr Opin Neurobiol 17: 609-618, 2007.

Coe B, Tomihara K, Matsuzawa M, Hikosaka O. Visual and anticipatory bias in three cortical eye fields of the monkey during an adaptive decision-making task. J Neurosci 22: 5081-5090, 2002.

Compte A, Brunel N, Goldman-Rakic PS, Wang XJ. Synaptic mechanisms and network dynamics underlying spatial working memory in a cortical network model. Cereb Cortex 10: 910-923, 2000.

Constantinidis C, Franowicz MN, Goldman-Rakic PS. Coding specificity in cortical microcircuits: a multiple-electrode analysis of primate prefrontal cortex. J Neurosci 21: 3646-3655, 2001a.

Constantinidis C, Franowicz MN, Goldman-Rakic PS. The sensory nature of mnemonic representation in the primate prefrontal cortex. Nat Neurosci 4: 311-316, $2001 \mathrm{~b}$.

Constantinidis C, Wang XJ. A neural circuit basis for spatial working memory. Neuroscientist 10: 553-565, 2004.

Conway ARA, Kane MJ, Engle RW. Working memory capacity and its relation to general intelligence. Trends Cogn Sci 7: 547-552, 2003. 
Courtney SM, Petit L, Maisog JM, Ungerleider LG, Haxby JV. An area specialized for spatial working memory in human frontal cortex. Science 279: 1347-1351, 1998.

DeSouza JFX, Everling S. Focused attention modulates visual responses in the primate prefrontal cortex. J Neurophysiol 91: 855-862, 2004.

D'Esposito M, Postle BR. The dependence of span and delayed-response performance on prefrontal cortex. Neuropsychologia 37: 1303-1315, 1999.

Dudchenko PA. An overview of the tasks used to test working memory in rodents. Neurosci Biobehav Rev 28: 699-709, 2004.

Everling S, Tinsley CJ, Gaffan D, Duncan J. Filtering of neural signals by focused attention in the monkey prefrontal cortex. Nat Neurosci 5: 671-676, 2002.

Frith CD, Friston K, Liddle PF, Frackowiak RS. Willed action and the prefrontal cortex in man: a study with PET. Proc Biol Sci 244: 241-246, 1991.

Funahashi S. Space representation in the prefrontal cortex. Prog Neurobiol 103: 131-155, 2013.

Funahashi S, Bruce CJ, Goldman-Rakic PS. Mnemonic coding of visual space in the monkey's dorsolateral prefrontal cortex. J Neurophysiol 61: 331-349, 1989.

Funahashi S, Bruce CJ, Goldman-Rakic PS. Visuospatial coding in primate prefrontal neurons revealed by oculomotor paradigms. J Neurophysiol 63: 814-831, 1990.

Funahashi S, Bruce CJ, Goldman-Rakic PS. Neuronal activity related to saccadic eye movements in the monkey's dorsolateral prefrontal cortex. J Neurophysiol 65: 1464-1483, 1991.

Funahashi S, Bruce CJ, Goldman-Rakic PS. Dorsolateral prefrontal lesions and oculomotor delayed-response performance: evidence for mnemonic "scotomas". J Neurosci 13: 1479-1497, 1993a.

Funahashi S, Chafee MV, Goldman-Rakic PS. Prefrontal neuronal activity in rhesus monkeys performing a delayed anti-saccade task. Nature 365: 753-756, $1993 \mathrm{~b}$.

Fuster JM. The Prefrontal Cortex. San Diego: Academic Press, 2008, 4th edition.

Goldman-Rakic PS, Funahashi S, Bruce CJ. Neocortical memory circuits. Cold Spring Harb Symp Quant Biol 55: 1025-1038, 1990.

Haynes JD, Sakai K, Rees G, Gilbert S, Frith C, Passingham RE. Reading hidden intentions in the human brain. Curr Biol 17: 323-328, 2007.

Hesselmann G, Kell CA, Eger E, Kleinschmidt A. Spontaneous local variations in ongoing neural activity bias perceptual decisions. Proc Natl Acad Sci U S A 105: 10984-10989, 2008.

Hyder F, Phelps EA, Wiggins CJ, Labar KS, Blamire AM, Shulman RG. "Willed action": a functional MRI study of the human prefrontal cortex during a sensorimotor task. Proc Natl Acad Sci U S A 94: 6989-6994, 1997. 
Judge SJ, Richmond BJ, Chu FC. Implantation of magnetic search coils for measurement of eye position: an improved method. Vision Res 20: 535-538, 1980.

Kane MJ, Engle RW. Working-memory capacity and the control of attention: the contributions of goal neglect, response competition, and task set to stroop interference. J Exp Psychol Gen 132: 47-70, 2003.

Kenet T, Bibitchkov D, Tsodyks M, Grinvald A, Arieli A. Spontaneously emerging cortical representations of visual attributes. Nature 425: 954-956, 2003.

Lau HC, Rogers RD, Haggard P, Passingham RE. Attention to intention. Science 303: 1208-1210, 2004a.

Lau HC, Rogers RD, Ramnani N, Passingham RE. Willed action and attention to the selection of action. Neuroimage 21: 1407-1415, 2004b.

Lebedev MA, Messinger A, Kralik JD, Wise SP. Representation of attended versus remembered locations in prefrontal cortex. PLoS Biol 2: e365, 2004.

Lennert T, Martinez-Trujillo J. Strength of response suppression to distracter stimuli determines attentional-filtering performance in primate prefrontal neurons. Neuron 70: 141-152, 2011.

Lennert T, Martinez-Trujillo JC. Prefrontal neurons of opposite spatial preference display distinct target selection dynamics. J Neurosci 33: 9520-9529, 2013.

Martinez-Conde S, Macknik SL, Hubel DH. Microsaccadic eye movements and firing of single cells in the striate cortex of macaque monkeys. Nat Neurosci 3: 251-258, 2000.

Matsushima A, Tanaka M. Different neuronal computations of spatial working memory for multiple locations within versus across visual hemifields. J Neurosci 34: 5621-5626, 2014.

Messinger A, Lebedev MA, Kralik JD, Wise SP. Multitasking of attention and memory functions in the primate prefrontal cortex. J Neurosci 29: 5640-5653, 2009.

Miller EK, Cohen JD. An integrative theory of prefrontal cortex function. Annu Rev Neurosci 24: 167-202, 2001.

Miyake A, Friedman NP, Emerson MJ, Witzki AH, Howerter A, Wager TD. The unity and diversity of executive functions and their contributions to complex "frontal lobe" tasks: a latent variable analysis. Cogn Psychol 41: 49-100, 2000.

Mochizuki K, Funahashi S. Opposing history effect of preceding decision and action in the free choice of saccade direction. J Neurophysiol 112: 923-932, 2014.

Mottaghy FM, Gangitano M, Sparing R, Krause BJ, Pascual-Leone A. Segregation of areas related to visual working memory in the prefrontal cortex revealed by rTMS. Cereb Cortex 12: 369-375, 2002.

Müller NG, Machado L, Knight RT. Contributions of subregions of the prefrontal cortex to working memory: evidence from brain lesions in humans. J Cogn Neurosci 14: 673-686, 2002. 
Ogawa T, Komatsu H. Differential temporal storage capacity in the baseline activity of neurons in macaque frontal eye field and area V4. J Neurophysiol 103: 2433-2445, 2010.

Platt ML, Glimcher PW. Neural correlates of decision variables in parietal cortex. Nature 400: 233-238, 1999.

Procyk E, Goldman-Rakic PS. Modulation of dorsolateral prefrontal delay activity during self-organized behavior. J Neurosci 26: 11313-11323, 2006.

R Core Team. R: A Language and Environment for Statistical Computing. R Foundation for Statistical Computing, Vienna, Austria, 2015.

Rainer G, Asaad WF, Miller EK. Memory fields of neurons in the primate prefrontal cortex. Proc Natl Acad Sci U S A 95: 15008-15013, 1998.

Rao SG, Williams GV, Goldman-Rakic PS. Isodirectional tuning of adjacent interneurons and pyramidal cells during working memory: evidence for microcolumnar organization in PFC. $J$ Neurophysiol 81: 1903-1916, 1999.

Robinson DA. A method of measuring eye movement using a scleral search coil in a magnetic field. IEEE Trans Biomed Eng 10: 137-145, 1963.

Rolls ET, Deco G. Prediction of decisions from noise in the brain before the evidence is provided. Front Neurosci 5: 33, 2011.

Rowe JB, Toni I, Josephs O, Frackowiak RS, Passingham RE. The prefrontal cortex: response selection or maintenance within working memory? Science 288: 1656-1660, 2000.

Sakai K, Rowe JB, Passingham RE. Active maintenance in prefrontal area 46 creates distractor-resistant memory. Nat Neurosci 5: 479-484, 2002.

Saperstein AM, Fuller RL, Avila MT, Adami H, McMahon RP, Thaker GK, Gold JM. Spatial working memory as a cognitive endophenotype of schizophrenia: assessing risk for pathophysiological dysfunction. Schizophr Bull 32: 498-506, 2006.

Sawaguchi T, Iba M. Prefrontal cortical representation of visuospatial working memory in monkeys examined by local inactivation with muscimol. J Neurophysiol 86: 2041-2053, 2001.

Shadlen MN, Newsome WT. Motion perception: seeing and deciding. Proc Natl Acad Sci U S A 93: 628-633, 1996.

Shadlen MN, Newsome WT. Neural basis of a perceptual decision in the parietal cortex (area LIP) of the rhesus monkey. J Neurophysiol 86: 1916-1936, 2001.

Shenoy KV, Sahani M, Churchland MM. Cortical control of arm movements: a dynamical systems perspective. Annu Rev Neurosci 36: 337-359, 2013.

Soon CS, Brass M, Heinze HJ, Haynes JD. Unconscious determinants of free decisions in the human brain. Nat Neurosci 11: 543-545, 2008. 
Tremblay S, Pieper F, Sachs A, Martinez-Trujillo J. Attentional filtering of visual information by neuronal ensembles in the primate lateral prefrontal cortex. Neuron 85: 202-215, 2015.

Tsodyks M, Kenet T, Grinvald A, Arieli A. Linking spontaneous activity of single cortical neurons and the underlying functional architecture. Science 286: 1943-1946, 1999.

Wang XJ. Decision making in recurrent neuronal circuits. Neuron 60: 215-234, 2008.

Wang XJ. The prefrontal cortex as a quintessential "cognitive-type" neural circuit: Working memory and decision making. In: Principles of Frontal Lobe Function., edited by Stuss DT, Knight RT, Oxford, UK: Oxford University Press, 2013.

Wang XJ, Tegnér J, Constantinidis C, Goldman-Rakic PS. Division of labor among distinct subtypes of inhibitory neurons in a cortical microcircuit of working memory. Proc Natl Acad Sci U S A 101: 1368-1373, 2004.

Watanabe K, Funahashi S. Prefrontal delay-period activity reflects the decision process of a saccade direction during a free-choice ODR task. Cereb Cortex 17 Suppl 1: i88-100, 2007.

Watanabe K, Igaki S, Funahashi S. Contributions of prefrontal cue-, delay-, and response-period activity to the decision process of saccade direction in a free-choice ODR task. Neural Netw 19: 1203-1222, 2006.

Zarahn E, Aguirre G, D’Esposito M. Replication and further studies of neural mechanisms of spatial mnemonic processing in humans. Brain Res Cogn Brain Res 9: 1-17, 2000.

Zarahn E, Aguirre GK, D'Esposito M. Temporal isolation of the neural correlates of spatial mnemonic processing with fMRI. Brain Res Cogn Brain Res 7: 255-268, 1999. 


\section{$998 \quad$ Figure Captions}

999

1000 Figure 1:

1001 (a) Task configuration. Schematic illustration of the two tasks. In the ICT, the monkey

1002 was required to make a memory-guided saccade toward the cued location. In the FCT,

1003 the monkey needed to choose one of two cued locations before making a saccade. (b)

1004 Preference indices (bars) and response times (lines) of each monkey averaged across

1005 eight bins of absolute directions. Preference index was expected to be 0.25 if the

1006 monkey does not exhibit directional preference. (c) Choice proportions and response

1007 times in the FCT for rotated cue locations relative to the receptive field of the neurons.

1008 Proportion of $\mathrm{T}_{\text {in }}$ choice (left) was calculated for each of the $\mathrm{T}_{\text {in }} \mathrm{vs}_{\mathrm{ipsi}}, \mathrm{T}_{\text {in }} \mathrm{vs}_{\mathrm{T}} \mathrm{T}_{\text {contra}}$,

1009 and $\mathrm{T}_{\text {in }}$ vs $\mathrm{T}_{\text {opp }}$ pair condition, along with the total proportion calculated by collapsing

1010 the pair conditions. Response times (middle) and normalized response times (right)

1011 were averaged for each response direction, along with the grand average by collapsing

1012 all the directions.

1013

1014 Figure 2: 
1015 Activity of two representative neurons. Neuronal firing in each condition was plotted

1016 separately for the ICT (top row) and three pair conditions that included $\mathrm{T}_{\text {in }}$ as one of

1017 the two cues in the FCT (bottom three rows; $\mathrm{T}_{\text {in }}$ Vs $\mathrm{T}_{\text {ipsi }}, \mathrm{T}_{\text {in }} \mathrm{vs}_{\mathrm{contra}}$, and $\mathrm{T}_{\text {in }} \mathrm{vs}$

$1018 \mathrm{~T}_{\text {opp }}$ conditions). The left half of each panel is aligned to the time from cue onset and

1019 the right half is aligned to saccade offset. Different colors in the histograms and

1020 rastergrams correspond to different directions of saccades. Both neurons exhibited

1021 directionally selective transient activation to presentation of the cue in the ICT. In each

1022 pair condition of the FCT, the left neuron (a) exhibited nearly equivalent activation to

1023 the presented cues regardless of which cue location was chosen later in that trial. In the

1024 right neuron (b), the strength of the transient response to the cues in the FCT was

1025 significantly larger when it was followed by the animal choosing the neuron's

1026 preferred direction, even though the $\mathrm{T}_{\text {in }}$ cue was presented along with the $\mathrm{T}_{\text {out }}$ cue in

1027 all three pair conditions.

1028

1029 Figure 3:

1030 Population histograms and the change in ROC values in directionally selective

1031 cue-period neurons. (a, c) Averaged histograms and the ROC transition in the ICT.

1032 Fifty-nine neurons exhibited a significant directionally selective transient response to

1033 the cue in the ICT. Different colors indicate different directions of saccades. In the ICT,

1034 neuronal activity decreased with presentation of the cue at a location other than the 
1035 neuron's preferred direction $\left(\mathrm{T}_{\mathrm{in}}\right)$, but the strength of the suppression was equivalent in

1036 the three $\mathrm{T}_{\text {out }}$ conditions. (b, d) Averaged histograms and the ROC transition in the

1037 FCT. In the FCT, the neurons exhibited differential activation that predicted the 1038 animal's subsequent choice of saccade direction. Different colors indicate the three

1039 pair conditions under investigation in the FCT. Solid and dotted lines in the histograms

1040 indicate the choice of the $\mathrm{T}_{\text {in }}$ and $\mathrm{T}_{\text {out }}$ directions later in that trial, respectively. The

1041 difference between solid and dotted lines with the same color (choice-predictive

1042 activity) was evident in the cue period, but actually started to appear before cue onset.

1043 An ROC analysis showed the same result. The increase in the ROC values from 0.5

1044 started $750 \mathrm{~ms}$ before the start of the cue period.

1045

1046 Figure 4:

1047 Population histograms of neurons with and without choice-predictive activity in the

1048 pre-cue and cue periods. Conventions for the histograms are the same as those in

1049 Fig. 2. Activity for $\mathrm{T}_{\text {in }}$ (solid) and $\mathrm{T}_{\text {out }}$ (dotted) choice trials in the three FCT pair

1050 conditions were plotted separately for choice-predictive $(\mathbf{a}, \mathrm{n}=38)$ and unpredictive (b,

$1051 \mathrm{n}=21)$ neurons. Choice-predictive neurons also exhibited directionally selective 1052 activity during the delay period. 
1054 Figure 5:

1055 Characteristics of firing properties of choice-predictive neurons. (a) Correlation

1056 between persistent directionally selective activity and choice-predictive activity. The

1057 strength of directionally selective activity in the delay period of the ICT (transverse

1058 axis, ROC values between $\mathrm{T}_{\text {in }}$ and $\mathrm{T}_{\text {out }}$ trials in 1000-1500 ms after the start of the

1059 delay period) was closely correlated with the strength of choice-predictive activity in

1060 the pre-cue and cue periods of the FCT (vertical axis, ROC values between $\mathrm{T}_{\text {in }}$ and

$1061 \mathrm{~T}_{\text {out }}$ trials in -1000 to $500 \mathrm{~ms}$ from cue onset). (b) Comparison of baseline

1062 sustainability between choice-predictive (black) and choice-unpredictive (gray)

1063 neurons using different lengths of intervals. Choice-predictive neurons were

1064 characterized by a greater sustainability of activation even when the two bins were

1065 separated by a long interval. (c-i) Comparison of firing properties and animal's

1066 behavior between choice-predictive and unpredictive neurons. (c) Strength of

1067 persistent delay-period activity in the ICT. (d) Baseline sustainability for 400-ms

1068 interval. (e) Serial correlation of ISI. (f) Absolute direction of the receptive field $(\mu)$.

1069 Dots indicate the center of the receptive field and error bars indicate the size. Zero

1070 corresponds to horizontal direction contralateral to the recorded hemisphere, and

1071 positive and negative values indicate upper and lower direction from the horizontal

1072 meridian, respectively. (g) Size of the receptive field $(1 / \sqrt{\beta})$. (h) Proportion of $T_{\text {in }}$

1073 choice in each pair condition and total proportion of $\mathrm{T}_{\text {in }}$ choice by collapsing pair 
1074 conditions. (i) Difference of response times between $\mathrm{T}_{\text {in }}$ choice and $\mathrm{T}_{\text {out }}$ choice trials.

1075 Choice-predictive neurons were characterized by their high persistence of activation 1076 (c-e) compared to choice-unpredictive neurons, without differences in absolute 1077 direction and size of the receptive fields $(\mathbf{f}, \mathbf{g})$ and the animal's behavior $(\mathbf{h}, \mathbf{i})$.

1079 Figure 6:

1080 Dynamics of neuronal activation using the state space based on a principal component 1081 analysis. (a, b) The activity of PFC neurons in each of the ICT (a) and FCT (b) 1082 conditions are shown as trajectories inside a 3-D principal component space. The 1083 activity around the cue and delay periods (from the start of the fixation period to 1500 1084 ms after the start of the delay period) in both the ICT and FCT was collectively used to 1085 construct a state space. The letters in the panels show the start of the pre-cue $(\mathrm{P})$, cue 1086 (C) and delay (D) periods, respectively. In the ICT (a), the activity of PFC neurons 1087 were indistinguishable at the start of the cue period. The trajectory in $\mathrm{T}_{\text {in }}$ cue condition 1088 then started to diverge from that in $\mathrm{T}_{\text {out }}$ cue conditions. In the FCT (b), the trajectories 1089 for $\mathrm{T}_{\text {in }}$ choice trials took similar courses to those for $\mathrm{T}_{\text {in }}$ cue condition in the ICT, 1090 while those for $\mathrm{T}_{\text {out }}$ choice trials resembled those for $\mathrm{T}_{\text {out }}$ cue conditions in the ICT.

1091 However, there was little separation between the trajectories for the $\mathrm{T}_{\text {in }}$ and $\mathrm{T}_{\text {out }}$ 1092 choice trials in the $\mathrm{T}_{\text {in }}$ vs $\mathrm{T}_{\text {ipsi }}$ pair condition compared to the other pair conditions. (c) 
1093 The distance between the trajectories for $\mathrm{T}_{\text {in }}$ choice and $\mathrm{T}_{\text {out }}$ choice trials in the state

1094 space. The trajectories for trials with different choices immediately diverged from each

1095 other in the cue period in the $\mathrm{T}_{\text {in }}$ vs $\mathrm{T}_{\text {contra }} / \mathrm{T}_{\text {opp }}$ conditions, but not in the $\mathrm{T}_{\text {in }} \mathrm{vs}_{\mathrm{ipsi}}$

1096 condition.

1097

1098 Figure 7:

1099 Construction of spatial representation in the FCT. (a, b) Each line shows the

1100 correlation coefficients between the neuronal activation pattern at each time bin in a

1101 given FCT condition and that of the pre-response period in a corresponding ICT

1102 condition in which the monkey made the same response. Data are separately plotted

1103 for $\mathrm{T}_{\text {in }}$ choice (a) and $\mathrm{T}_{\text {out }}$ choice (b) trials. Different colors indicate different pair

1104 conditions in the FCT. Thick solid lines show ranges of significant correlation in each

1105 task condition. Triangles at the top show the onset of significant correlation that lasted

1106 through the delay period. In the $T_{\text {in }}$ vs $T_{\text {contra }} / T_{\text {opp }}$ pair conditions, significant

1107 correlation began around the start of the cue period. In the $\mathrm{T}_{\text {in }} \mathrm{vs}_{\mathrm{ipsi}}$ pair condition,

1108 significant correlation was observed at the end of the cue period in $\mathrm{T}_{\text {in }}$ choice trials

1109 and was not observed in $\mathrm{T}_{\text {out }}$ choice trials. (c) Result of a similar correlation analysis

1110 calculated between $\mathrm{T}_{\text {out }}$ choice trials in the FCT and $\mathrm{T}_{\text {in }}$ cue trials in the ICT. The

1111 neuronal activation pattern in FCT trials with $\mathrm{T}_{\text {out }}$ choice started to diverge from that 
1112 in ICT trials with a $\mathrm{T}_{\text {in }}$ cue before the start of the cue period in the $\mathrm{T}_{\text {in }} \mathrm{vs} \mathrm{T}_{\text {contra }} / \mathrm{T}_{\text {opp }}$

1113 conditions. However, a significant negative correlation was not observed until the

1114 delay period in the $\mathrm{T}_{\text {in }} \mathrm{vs}_{\mathrm{ipsi}}$ pair condition.

1115 
Fig. 1

(a) Behavioral tasks

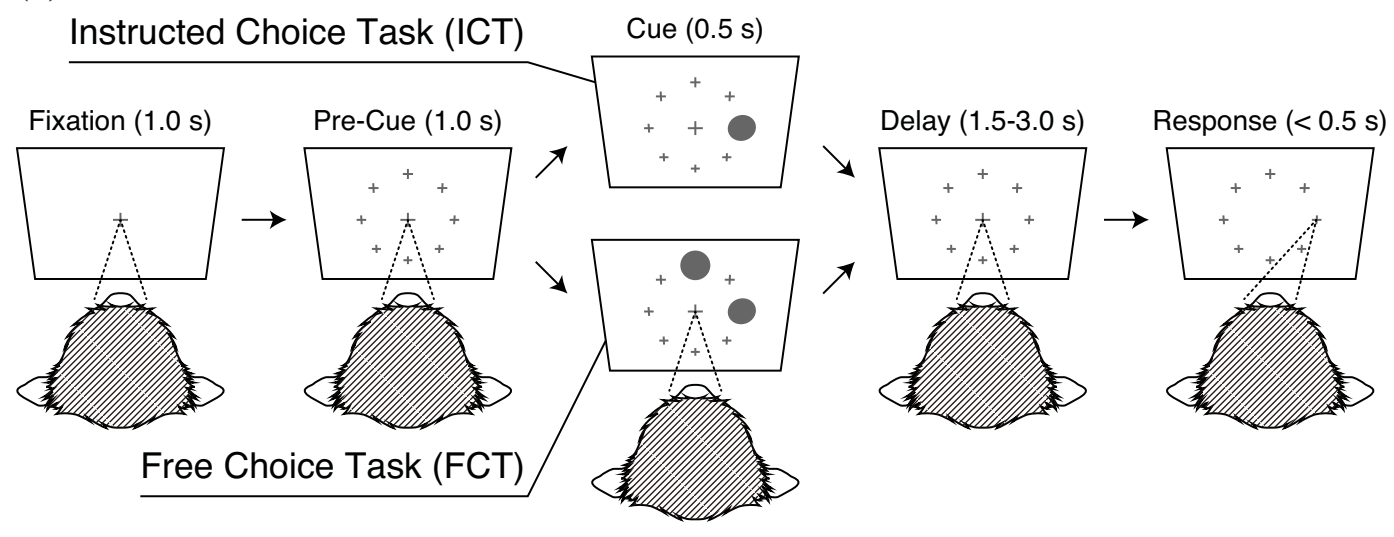

(b) Task performance for absolute directions
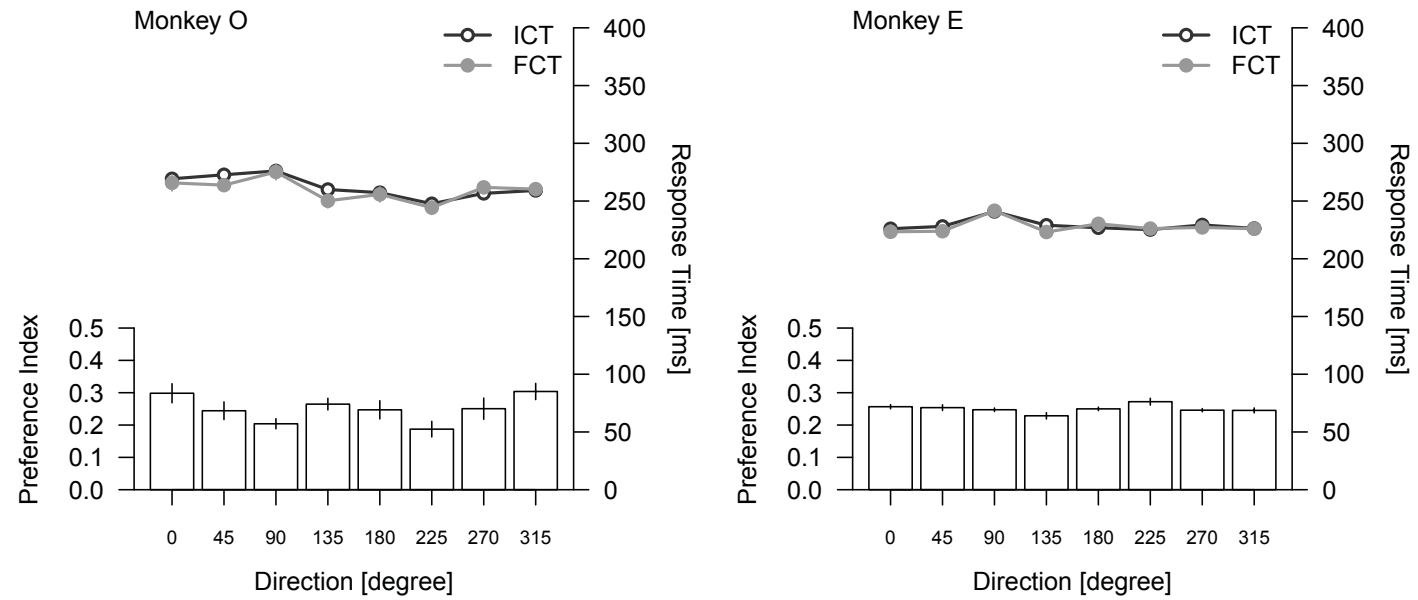

(c) Task performance for relative directions in the FCT
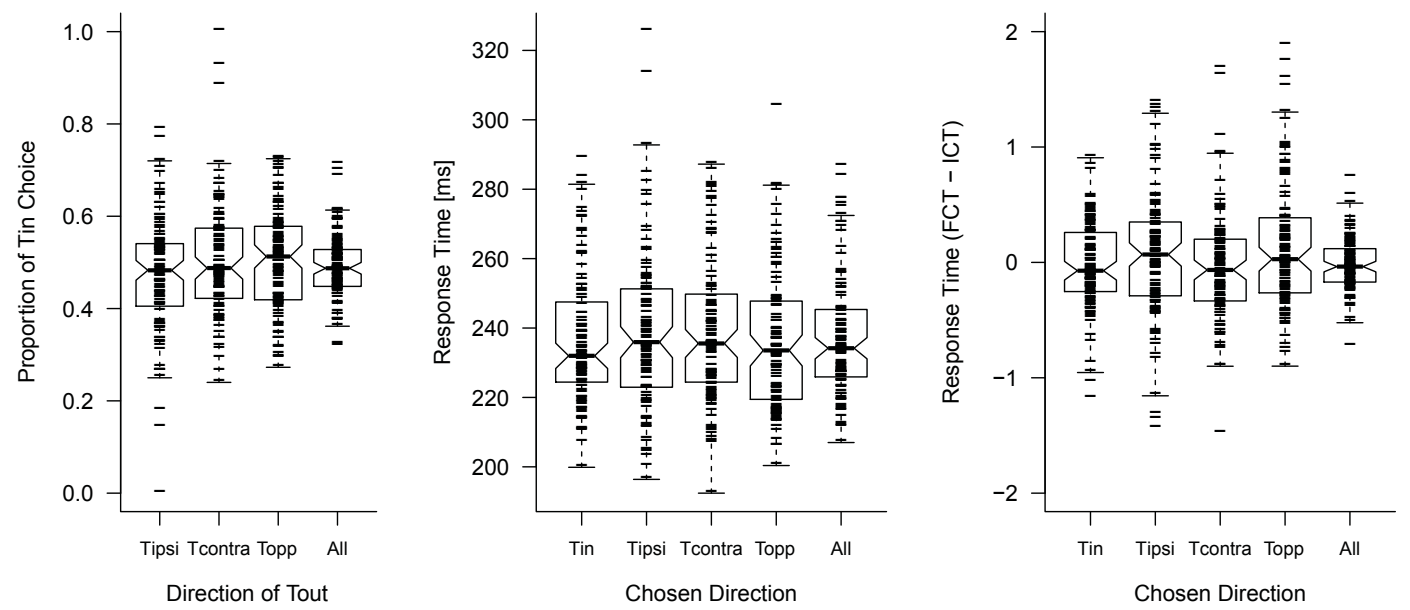
Fig. 2

(a) Choice-unpredictive neuron

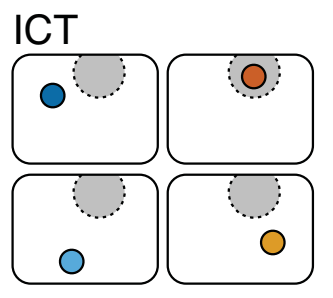

FCT

Tin vs Tipsi
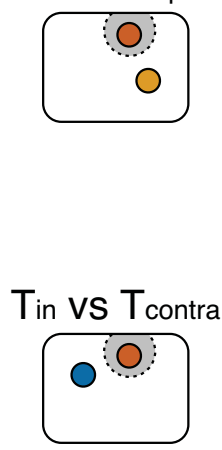

Tin vs Topp
$\vdots$
0

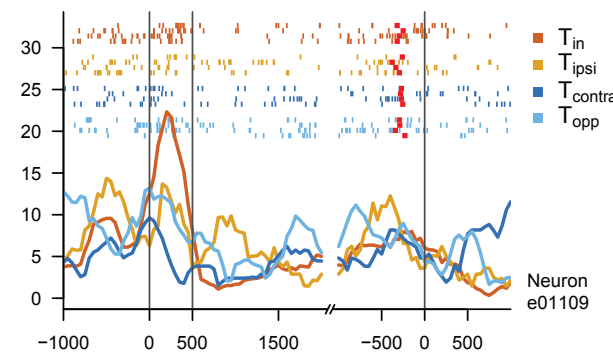

(b) Choice-predictive neuron
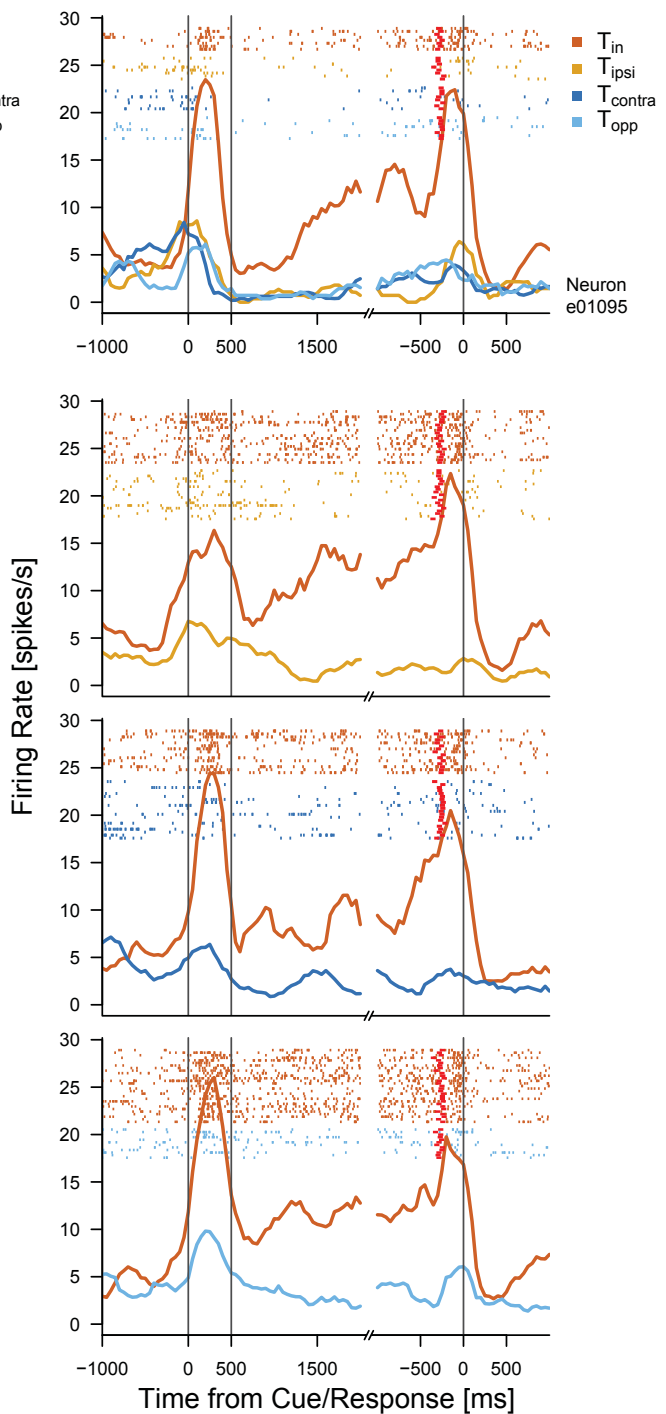
Fig. 3
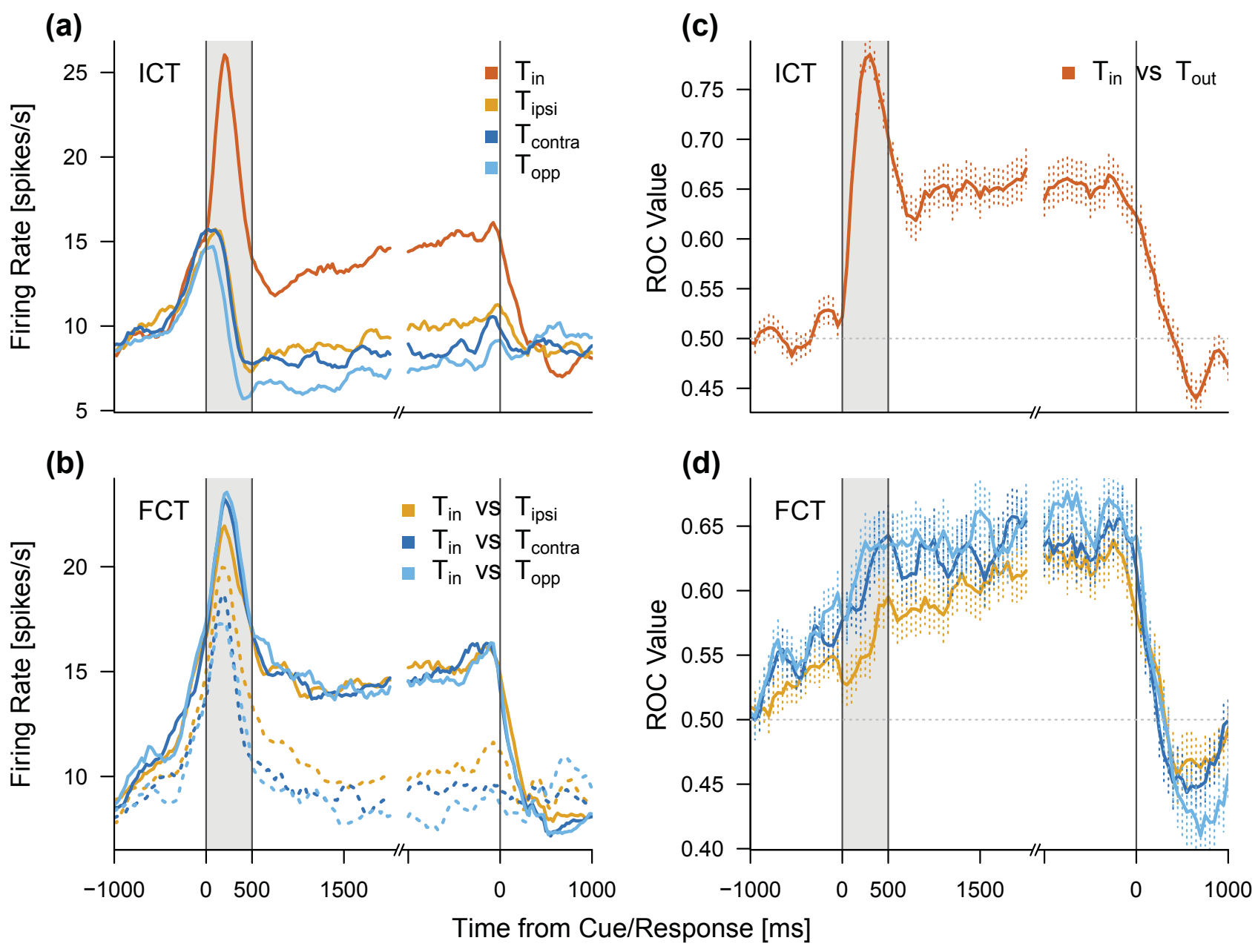
Fig. 4

(a) Choice-predictive neurons

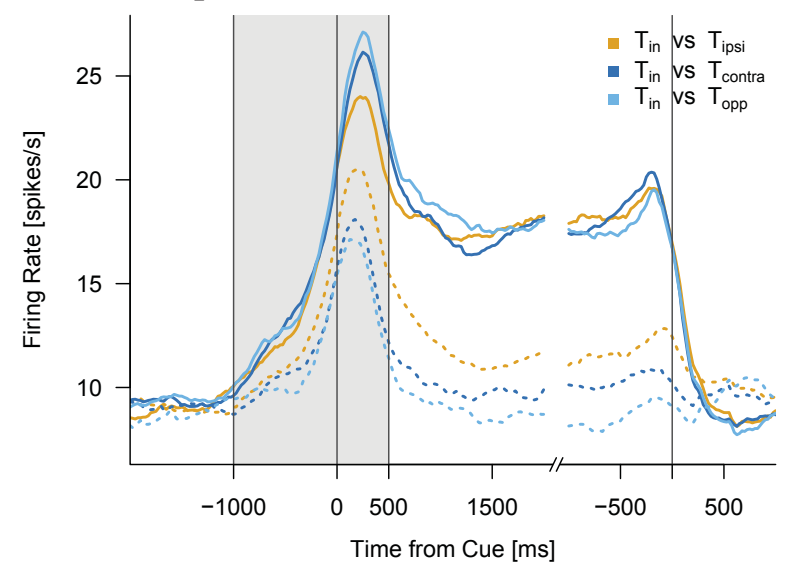

(b) Choice-unpredictive neurons

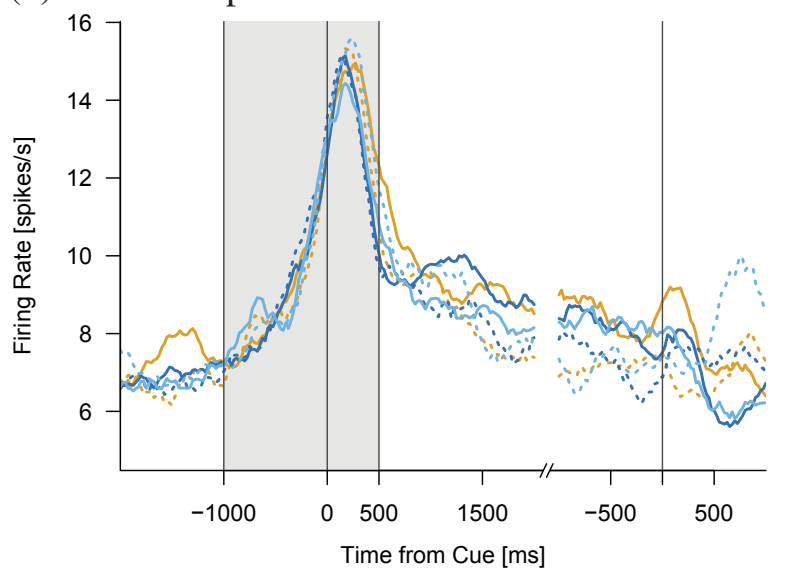


Fig. 5

(a)

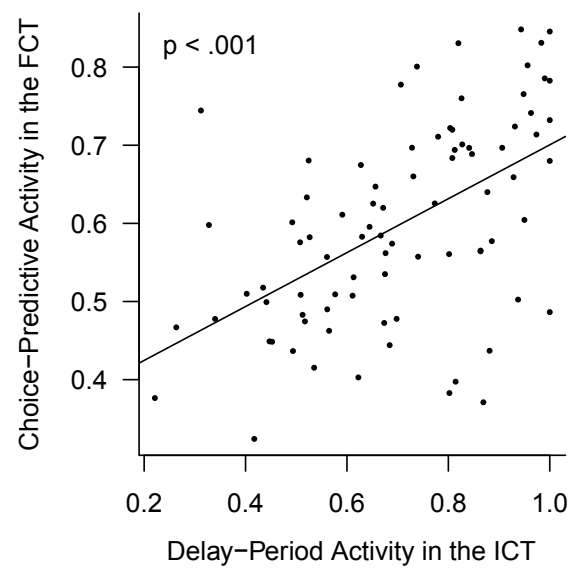

(b)

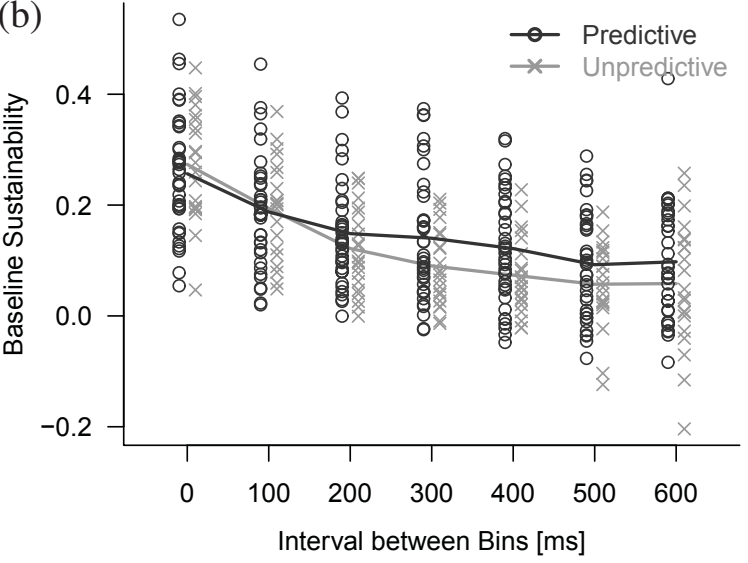

(c)

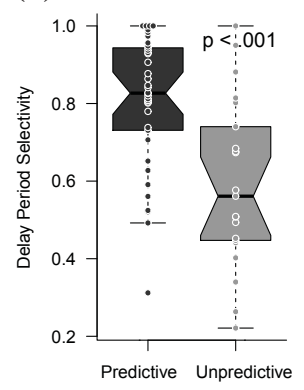

(d)

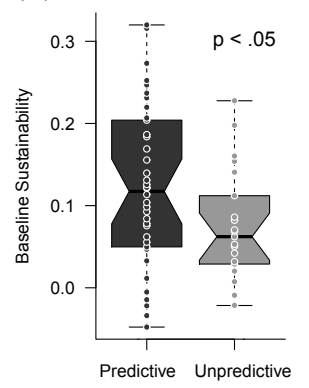

(e)

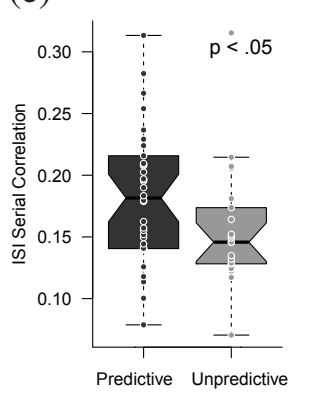

(f)

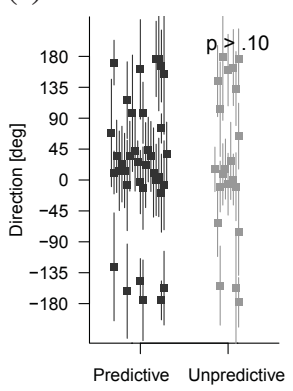

(g)

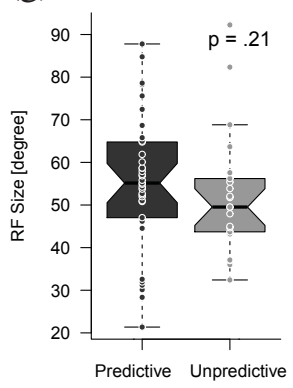

(h)

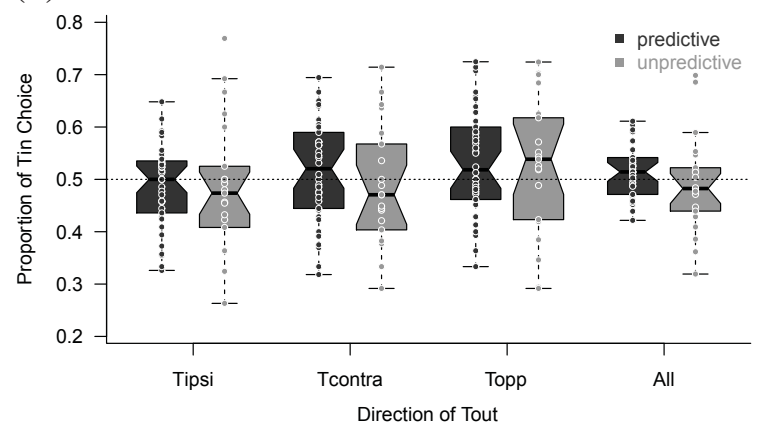

(i)

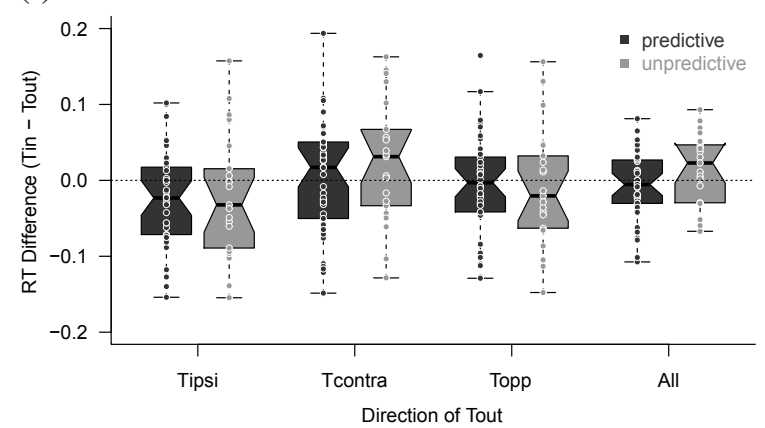


Fig. 6
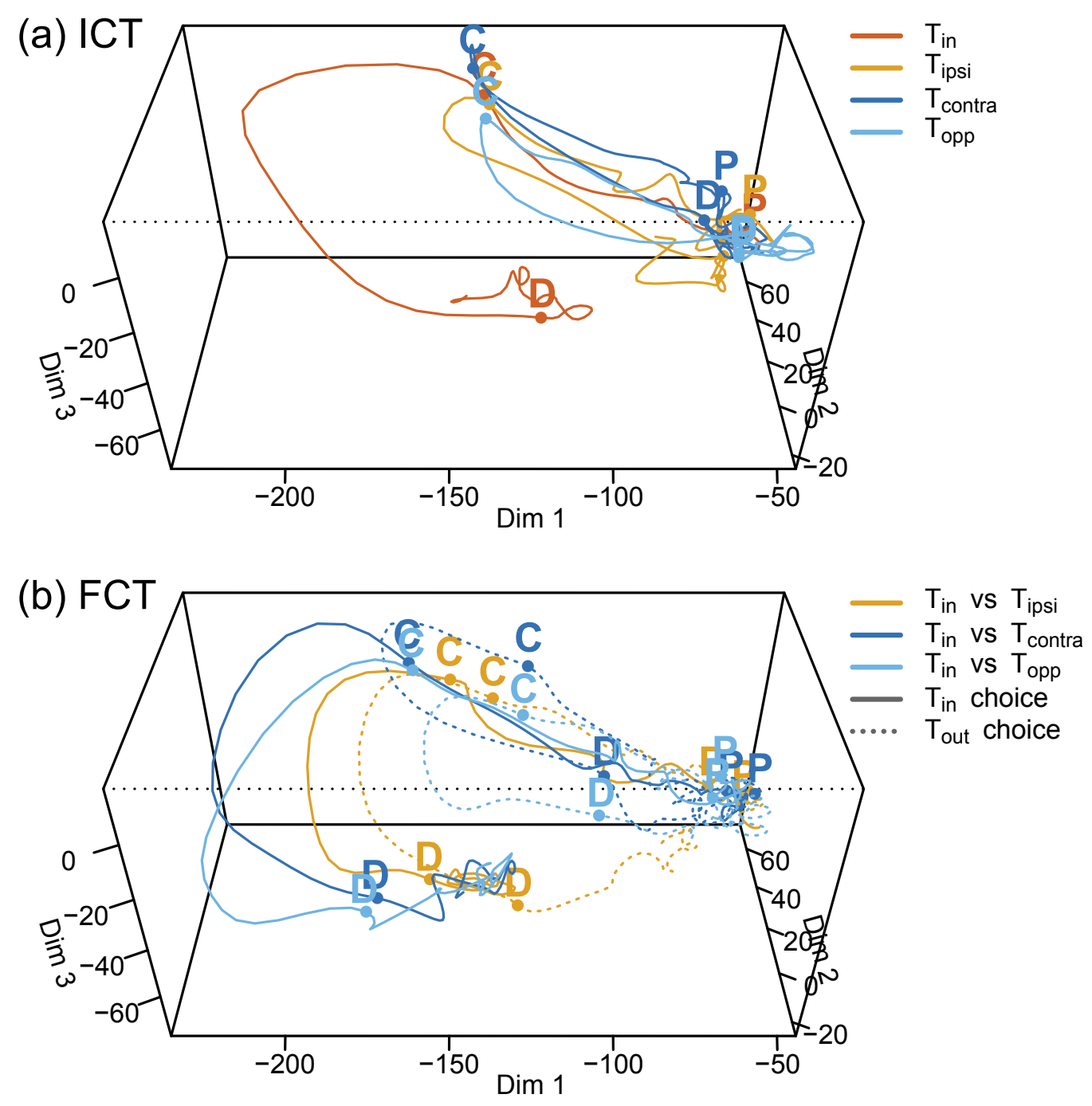

(c) Distance in the State Space

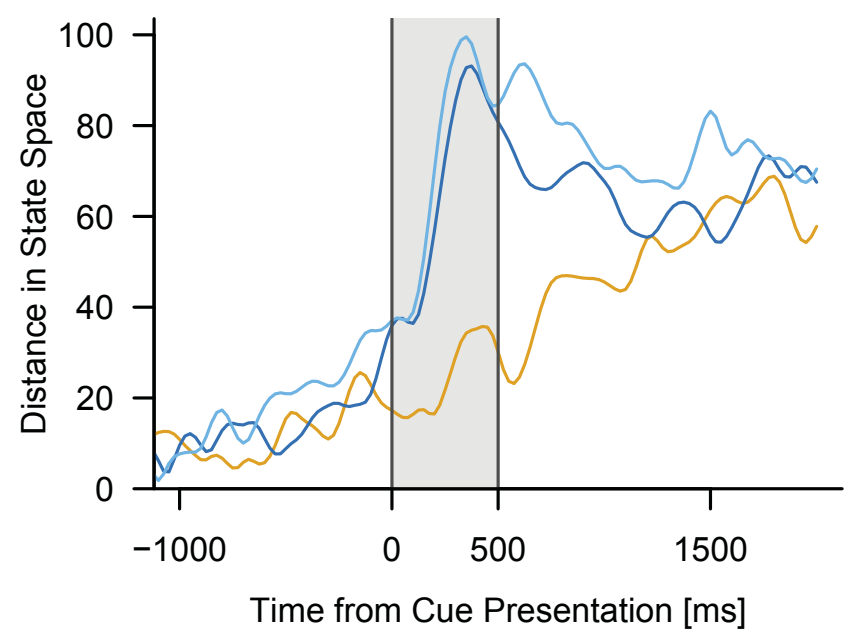


Fig. 7

(a) $\mathrm{T}_{\text {in }}$ choice FCT $\times \mathrm{T}_{\text {in }}$ cue ICT

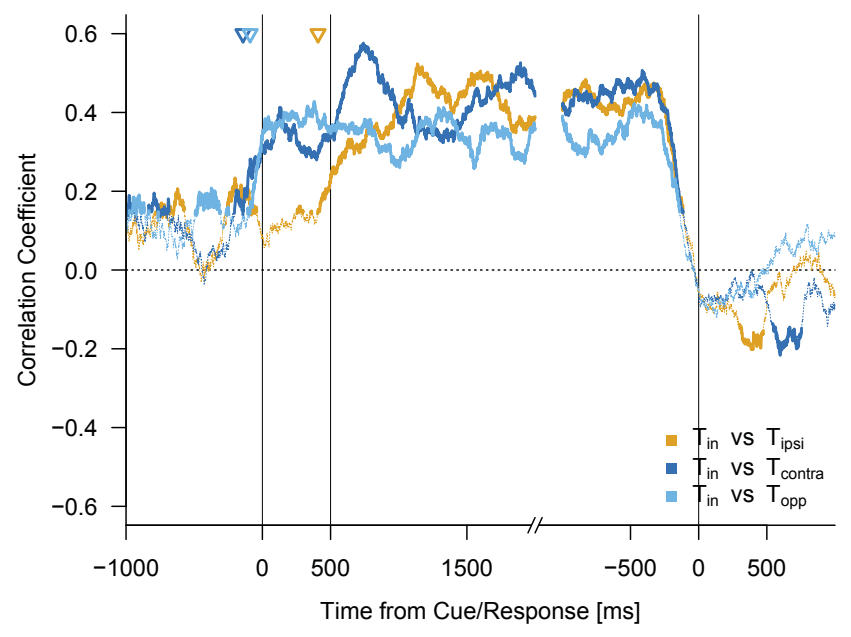

(b) $\mathrm{T}_{\text {out }}$ choice FCT $\times \mathrm{T}_{\text {out }}$ cue ICT

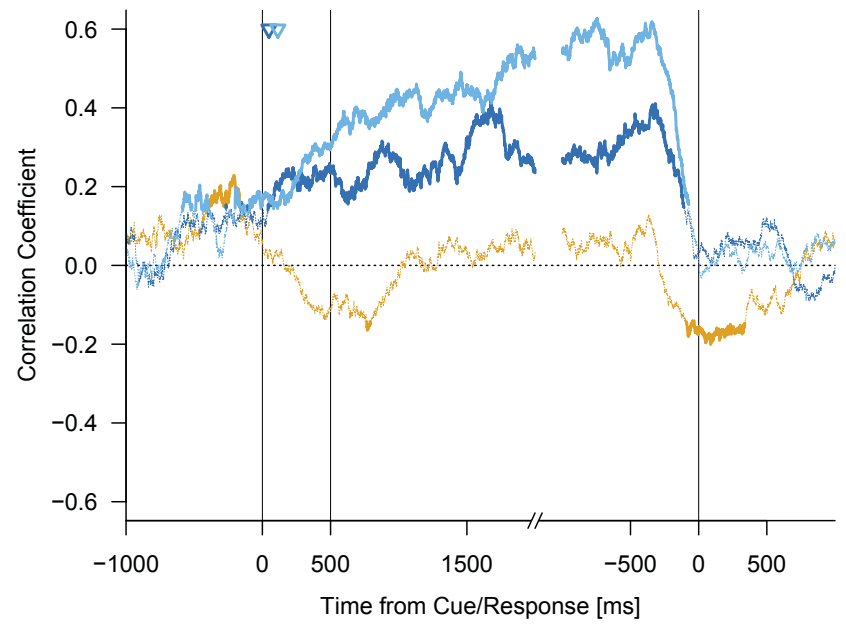

(c) $\mathrm{T}_{\text {out }}$ choice FCT $\times \mathrm{T}_{\text {in }}$ cue ICT

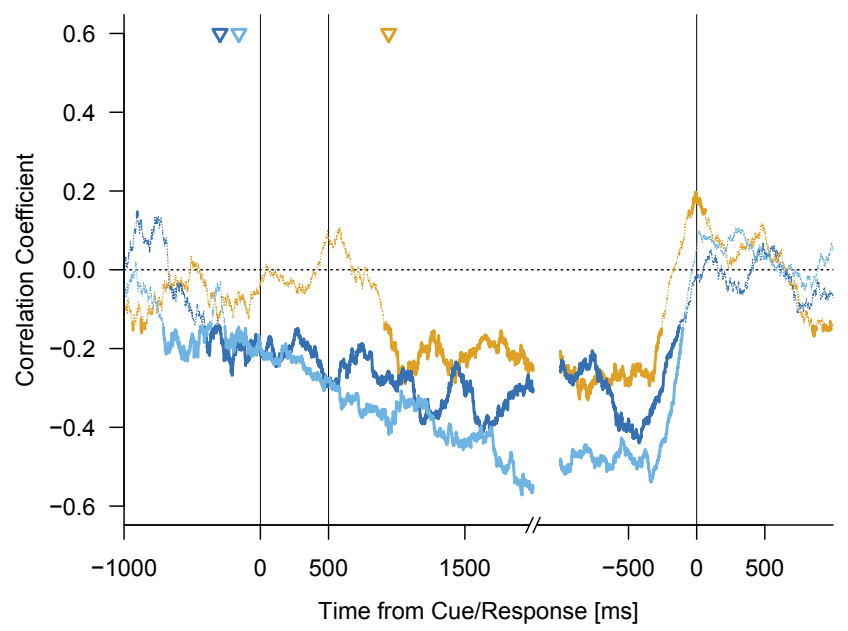

